\title{
The scale problem in quantifying aerosol indirect effects
}

\author{
A. McComiskey ${ }^{1,2}$ and G. Feingold ${ }^{2}$ \\ ${ }^{1}$ Cooperative Institute for Research in Environmental Sciences, University of Colorado, Boulder, USA \\ ${ }^{2}$ NOAA Earth System Research Laboratory, Boulder, USA
}

Correspondence to: A. McComiskey (allison.mccomiskey@noaa.gov)

Received: 10 September 2011 - Published in Atmos. Chem. Phys. Discuss.: 27 September 2011

Revised: 16 December 2011 - Accepted: 3 January 2012 - Published: 23 January 2012

\begin{abstract}
A wide range of estimates exists for the radiative forcing of the aerosol effect on cloud albedo. We argue that a component of this uncertainty derives from the use of a wide range of observational scales and platforms. Aerosol influences cloud properties at the microphysical scale, or the "process scale", but observations are most often made of bulk properties over a wide range of resolutions, or "analysis scales". We show that differences between process and analysis scales incur biases in quantification of the albedo effect through the impact that data aggregation and computational approach have on statistical properties of the aerosol or cloud variable, and their covariance. Measures made within this range of scales are erroneously treated as equivalent, leading to a large uncertainty in associated radiative forcing estimates. Issues associated with the coarsening of observational resolution particular to quantifying the albedo effect are discussed. Specifically, the omission of the constraint on cloud liquid water path and the separation in space of cloud and aerosol properties from passive, space-based remote sensors dampen the measured strength of the albedo effect. We argue that, because of this lack of constraints, many of these values are in fact more representative of the full range of aerosol-cloud interactions and their associated feedbacks. Based on our understanding of these biases we propose a new observationally-based and process-model-constrained, method for estimating aerosol-cloud interactions that can be used for radiative forcing estimates as well as a better characterization of the uncertainties associated with those estimates.
\end{abstract}

\section{Introduction}

Boundary layer clouds have been identified as a major source of uncertainty in climate sensitivity and climate change (Bony and Dufresne, 2006; Medeiros et al., 2008). The influence of aerosol particles on these clouds, via modification to microphysical processes, further contributes to this uncertainty. Aerosol has potentially substantial impacts on cloud radiative forcing ("aerosol indirect effects"), cloud-climate feedbacks, and water resources through changing patterns of precipitation; however, quantifying the associated mechanisms and impacts through observation, and representing those processes in models, has proven to be extremely challenging.

To date, only the first aerosol indirect effect, or albedo effect (Twomey, 1974), has been considered a radiative forcing and therefore included in Intergovernmental Panel on Climate Change radiative forcing estimates (Forster, 2007). The underlying physics for the albedo effect is well established: more aerosol results in more nuclei for cloud droplet formation, higher droplet concentrations, smaller droplet effective radius, and higher cloud albedo (all else equal). However the sensitivity of cloud microphysical (and therefore albedo) response to an increase in aerosol is still a matter of much debate, and at the heart of this study. The sign of this forcing is agreed to be negative but a large uncertainty in the estimated magnitude has persisted through time (Lohmann et al., 2010). The IPCC estimate comprises results from general circulation models (GCMs) and includes no estimates from observations alone. A few studies have produced purely observational estimates of the first indirect effect radiative forcing (e.g., Quaas et al., 2008; Lebsock et al., 2008) and inverse calculations based on observations have also been performed 
(e.g., Murphy et al., 2009). These tend to be at the low end of the range produced by GCMs.

Indirect effects related to cloud water variability and precipitation that potentially affect cloud amount and lifetime, traditionally considered feedbacks, have an even more poorly quantified impact on the radiation budget (Quaas et al., 2009; Lohmann et al., 2010). The numerous process studies that have attempted to assess the magnitude of these effects have generated conflicting answers, and even the sign of the cloud water response to changes in the aerosol is in question (Albrecht, 1989; Ackerman et al., 2004; Brenguier et al., 2003a; Matsui et al., 2006; Xue et al., 2008; Lebsock et al., 2008). While the focus of this study is on the albedo effect, many of the issues presented are relevant to indirect forcing in the broadest sense.

This paper will show that progress in narrowing the uncertainty range in the albedo effect has been hampered by neglect of important observational aspects of aerosol-cloud interaction metrics. First, obtaining direct, independent, and collocated measurements of each pertinent variable is difficult, but required. Second, there is a range of observational scales or "analysis scales" to consider that are usually different from the scale of the driving mechanism or "process scale". Due to the effects of averaging on statistics, an analysis at the process scale is not equivalent to that made at coarser scales, resulting in metrics that may be too high or too low. The most accurate representation of a process results from an analysis in which the process scale and analysis scale are the same. Current analyses of the cloud-albedo effect span scales from the microphysical (the process scale) to the global (see references in Table 1). This spectrum of analyses has grown out of an interest to link important microphysical processes with the resulting radiative impacts at larger, climatically relevant (meso-to-global) scales, but also contributes directly to uncertainty. Finally, aerosol and cloud properties, and thus aerosol-cloud interaction processes, are highly spatially distributed. Distributing metrics that are either too high or too low uniformly over space, as is often done in climate models, further biases global estimates of the effect, and increases uncertainty.

It is our assertion that disparities in scale among various physical processes, inconsistencies in scale and computational approach among observations from various platforms, and disparities in the scales of representations (parameterizations) in models are responsible for a large part of the confusion in estimating the magnitude of indirect effects. The challenge can be broadly posed as follows: how does one represent variable, yet potentially strong local processes at coarse scales? An assessment of the characteristic spatial variability of aerosol and cloud properties is required, as is a consideration of analysis scales that are representative of the process, yet still accessible to global studies. The primary goals of this paper are to identify key factors that contribute to the differences in the scale-dependent range of aerosolcloud interaction metrics found in the literature and charac- terize the physical meaning of this spectrum of results. An outcome of this work is a proposed methodology for deriving an observationally-based and process-model-constrained estimate of radiative forcing that can be applied to different cloud regimes and aggregated up to the global scale.

\section{Aggregation and scale biases in statistics}

\subsection{Current state of understanding aerosol-cloud interactions}

Among the aerosol indirect effects, the IPCC has to date estimated the radiative forcing of the first indirect effect, or albedo effect (Twomey, 1974) only. This quantity has the largest uncertainty of all of the radiative forcings and is also the only estimate derived solely from model results. A breakdown of the radiative forcing estimates by each of the IPCC Fourth Assessment Report (AR4) models is shown in Fig. 1a. The closed circles indicate models that represent the cloudalbedo effect through the use of drop activation parameterizations and the open circles indicate models that use satellitebased empirical parameterizations. The models that apply empirical relationships between cloud and aerosol properties consistently predict the weakest radiative forcing. The latter are similar in magnitude to the purely satellite-based assessments such as those reported e.g., by Quaas et al. (2008), although these estimates are not included in AR4. Empirical estimates of aerosol-cloud interactions derive from a range of in situ airborne measurements, ground-based remote sensing, and space-based remote sensing of aerosol and cloud properties. Twomey (1974) used airborne, process-scale measurements to show that an increase in cloud condensation nuclei from pollution would result in brighter clouds by increasing cloud optical depth, all else being equal. This approach required the cloud water variable be constrained in order to assess the impact of the aerosol on cloud albedo while controlling for other impacts on the cloud albedo. To quantify the microphysical component of the albedo effect, Feingold et al. (2001) proposed a metric IE $=-d \ln r_{\mathrm{e}} / d \ln \tau_{\mathrm{a}}$, where $r_{\mathrm{e}}$ is the cloud drop effective radius and $\tau_{\mathrm{a}}$, the aerosol optical depth, holding cloud liquid water constant for all calculations. Later, the terminology for this calculation was changed to ACI (aerosol-cloud interactions) to clarify that the result represents not the indirect effect, which is a response of cloud albedo to aerosol, but instead the microphysical response of the albedo effect (McComiskey et al., 2009). Several other terminologies have been used in the literature, but for consistency ACI will be used throughout this work.

$\mathrm{ACI}$ has been reported or derived later from measurements published in the literature for almost two decades. A variety of proxies has been used to represent the aerosol particles affecting the cloud, including aerosol number concentration $N_{\mathrm{a}}, \tau_{\mathrm{a}}$, and aerosol index $\mathrm{AI}$ (the product of $\tau_{\mathrm{a}}$ and the Ångström exponent), all of which will henceforth be denoted 
Table 1. References used in Fig 1b. All studies address low or liquid clouds.

\begin{tabular}{|c|c|c|c|c|c|c|}
\hline & $\begin{array}{l}\text { method/ } \\
\text { instrument }\end{array}$ & $\begin{array}{l}\text { parameters } \\
\text { used }\end{array}$ & $\mathrm{ACI} \tau$ & resolution & $\begin{array}{l}\text { temporal } \\
\text { averaging }\end{array}$ & $L^{*}$ \\
\hline \multicolumn{7}{|l|}{ Ground } \\
\hline Feingold et al. (2003) & RS (remote sensing) & & 0.10 & $20 \mathrm{~s}$ & & yes \\
\hline Garrett et al. (2004) & RS+in situ & & 0.15 & $30 \mathrm{~min}$ & & yes \\
\hline Kim et al. (2008) & RS+in situ & & 0.15 & $5 \mathrm{~min}$ & & yes \\
\hline Lihavainen et al. (2008) & in situ & & 0.24 & $1 \mathrm{~h}$ & & yes \\
\hline McComiskey et al. (2009) & RS+in situ & & 0.16 & $20 \mathrm{~s}$ & & yes \\
\hline \multicolumn{7}{|l|}{ Airborne } \\
\hline Twohy et al. (2005) & in situ & & 0.27 & $10-60 \mathrm{~min}$ & & \\
\hline Raga and Jonas (1993) & in situ & & 0.09 & NA & & no \\
\hline Martin et al. (1994) & in situ & & 0.25 & $30 \mathrm{~km}$ & & \\
\hline Gultepe et al. (1996) & in situ & & 0.22 & $\sim 12 \mathrm{~km}$ & & yes \\
\hline O’Dowd et al. (1999) & in situ & & 0.20 & & & \\
\hline McFarquhar and Heymsfield (2001) & in situ & & 0.11 & & & \\
\hline Ramanathan (2001) & in situ & & $0.21-0.33$ & & & \\
\hline Lu et al. (2007) & in situ & & 0.19 & $30 \mathrm{~km}$ & & \\
\hline Lu et al. (2008) & in situ & & 0.14 & leg means & & \\
\hline \multicolumn{7}{|l|}{ Satellite } \\
\hline Nakajima et al. (2001) & AVHRR & $N_{\mathrm{d}} ; N_{\mathrm{a}}$ & 0.17 & $0.5^{\circ}$ & 4 months & \\
\hline Bulgin et al. (2008) & ASTER-2 & $r_{\mathrm{e}} ; \tau_{\mathrm{a}}$ & $0.10-0.16(0.13)$ & $1^{\circ}$ & seasonal $/ 3$ months & no \\
\hline Kaufman et al. (2005) & MODIS & $r_{\mathrm{e}} ; \mathrm{AI}$ & $0.046-0.174(0.0975)$ & $1^{\circ}$ & simultaneous/daily & no \\
\hline Sekiguchi et al. (2003) & AVHRR & $r_{\mathrm{e}} ; N_{\mathrm{a}}$ & 0.1 & $2.5^{\circ}$ & daily & no \\
\hline Lebsock et al. (2008) & MODIS & $r_{\mathrm{e}} ; \mathrm{AI}$ & 0.07 & $1 \mathrm{~km}$ to $1^{\circ}$ & simultaneous & no \\
\hline Sekiguchi et al. (2003) & POLDER & $r_{\mathrm{e}} ; N_{\mathrm{a}}$ & 0.07 (ocean) & $2.5^{\circ}$ & monthly & no \\
\hline Quaas et al. (2006) & MODIS & $N_{\mathrm{d}} ; \tau_{\mathrm{a}}$ & 0.04 & $3.75^{\circ} \times 2.5^{\circ}$ & daily & \\
\hline Quaas et al. (2004) & POLDER & $r_{\mathrm{e}} ; \mathrm{AI}$ & 0.04 (ocean)/0.012(land) & $3.75^{\circ} \times 2.5^{\circ}$ & simultaneous & no \\
\hline \multicolumn{7}{|l|}{ Satellite + Model } \\
\hline Breon et al. (2002) & POLDER + back trajectories & $r_{\mathrm{e}} ; \tau_{\mathrm{a}}, \mathrm{AI}$ & 0.085 (ocean)/0.04 (land) & $150 \mathrm{~km}$ & 3 months & no \\
\hline Chameides et al. (2002) & ISCCP + CTM & $\tau_{\mathrm{c}} ; \tau_{\mathrm{a}}$ & 0.17 (all)/0.14 (low cloud) & $280 \mathrm{~km}$ & annual & no \\
\hline
\end{tabular}

* $L$-constraint used in calculation of ACI.

by $\alpha$. Similarly, various proxies have been used to represent the cloud response to the change in aerosol, e.g., cloud optical depth $\tau_{\mathrm{c}}$, cloud drop number concentration $N_{\mathrm{d}}$, and $r_{\mathrm{e}}$. Using data for which the analysis scale closely matched the process scale, McComiskey et al. (2009) showed empirically that there is consistency amongst calculations of ACI using different microphysical proxies, provided the appropriate constraint on cloud liquid water path $L$ is applied. Thus,

$$
\begin{aligned}
& \mathrm{ACI}_{\tau}=\left.\frac{\partial \ln \tau_{\mathrm{c}}}{\partial \ln \alpha}\right|_{\mathrm{L}} \quad 0<\mathrm{ACI}_{\tau}<0.33 \\
& \mathrm{ACI}_{\mathrm{r}}=-\left.\frac{\partial \ln r_{\mathrm{e}}}{\partial \ln \alpha}\right|_{\mathrm{L}} \quad 0<\mathrm{ACI}_{\mathrm{r}}<0.33 \\
& \mathrm{ACI}_{\mathrm{N}}=\frac{d \ln N_{\mathrm{d}}}{d \ln \alpha} \quad 0<\mathrm{ACI}_{\mathrm{N}}<1 \\
& \mathrm{ACI}_{\tau}=-\mathrm{ACI}_{\mathrm{r}}=\frac{1}{3} \mathrm{ACI}_{\mathrm{N}} .
\end{aligned}
$$

Figure $1 \mathrm{~b}$ presents a representative selection of $\mathrm{ACI}_{\tau}$ values $(0 \leq \mathrm{ACI} \leq 0.33)$ from the literature originating from a

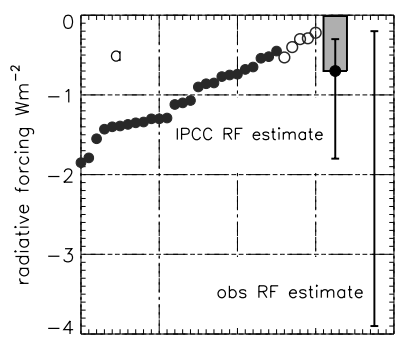

IPCC models

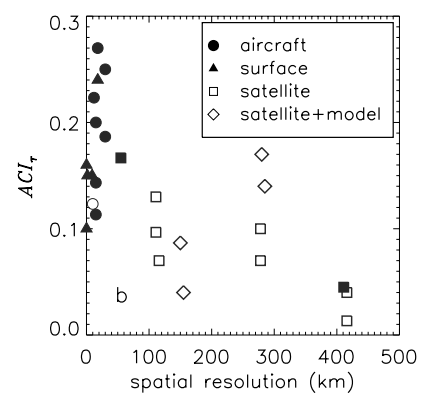

Fig. 1. (a) Radiative forcing estimates by each IPCC model and the overall IPCC radiative forcing estimate in comparison to an observational estimate for the cloud albedo effect resulting from the values in $1 \mathrm{~b}$. (b) Values from the literature quantifying the albedo effect using some variant of Eq. (1), expressed here as $\mathrm{ACI}_{\tau}$, and plotted as a function of scale (resolution) of the study. Closed symbols are those that calculate the original variant of ACI with constraint on cloud water and open symbols are those that ignore the constraint on cloud water. 
range of observational platforms. Closed symbols denote studies where calculations were constrained by $L$ and open symbols denote studies for which this constraint was ignored. It is clear that quantification of the albedo effect is sensitive to scale and the constraint on $L$. The studies that occupy the coarsest resolutions on this plot were intentionally undertaken at resolutions that are comparable to GCM grid cell sizes in order to produce evaluation datasets or empirical parameterizations for those models. The association between weak radiative forcing and these coarse-scale parameterizations as opposed to stronger radiative forcing from both microphysical scale observations and model schemes becomes evident.

Published ACI values span almost the entire physically meaningful range from 0 to 0.33 (see Table 1). Data types used as input to these calculations range from those in which the process and analysis scales are closely matched to those in which the analysis scales are highly aggregated relative to the process scale. This begs the question: to what extent are these values meaningful, and how might they be applied in GCMs?

Observational estimates of forcing have been omitted in the overall radiative forcing estimate of the albedo effect in the IPCC AR4, so we perform rough calculations based on ACI values drawn from the literature. At the right of Fig. 1a, the overall IPCC radiative forcing (grey bar with range) is compared to a rough, 1-D (plane-parallel) calculation of what the range of forcing for the observations in Fig. $1 \mathrm{~b}$ would be, following radiative transfer calculations in McComiskey and Feingold (2008). The calculations assume a factor of 3 increase in cloud condensation nucleus concentrations $N_{\mathrm{CCN}}$ (from $100 \mathrm{~cm}^{-3}$ to $300 \mathrm{~cm}^{-3}$ ) and a global average liquid water cloud cover of $25 \%$ with mean $L=125 \mathrm{~g} \mathrm{~m}^{-2}$. ACI is varied over nearly the entire range of observed values from Fig. 1b. The result is a range in forcing from -0.2 to $-3.9 \mathrm{~W} \mathrm{~m}^{-2}$, much larger than the range estimated from GCMs. Figure 2 shows the variability in forcing as a function of ACI for various $L$ and CCN perturbations for 1-D or plane-parallel conditions ( $100 \%$ cloud cover). While this is a rudimentary estimate of the range of radiative forcing from observations with broad assumptions, it illustrates that observationally-based radiative forcing estimates of this kind are too variable to be useful in global observational analyses or model parameterizations.

If uncertainties in radiative forcing of aerosol indirect effects are to be reduced, it is necessary to understand what drives the scale biases seen in Fig. 1, both in how they relate to quantifying the albedo effect, and also in how they may reflect on analyses of all indirect effects including, for example, the impact of aerosol on cloud cover and $L$. In the following sections, we attempt to define the factors contributing to these biases and provide some potential solutions that allow for a useable observationally-based estimate.

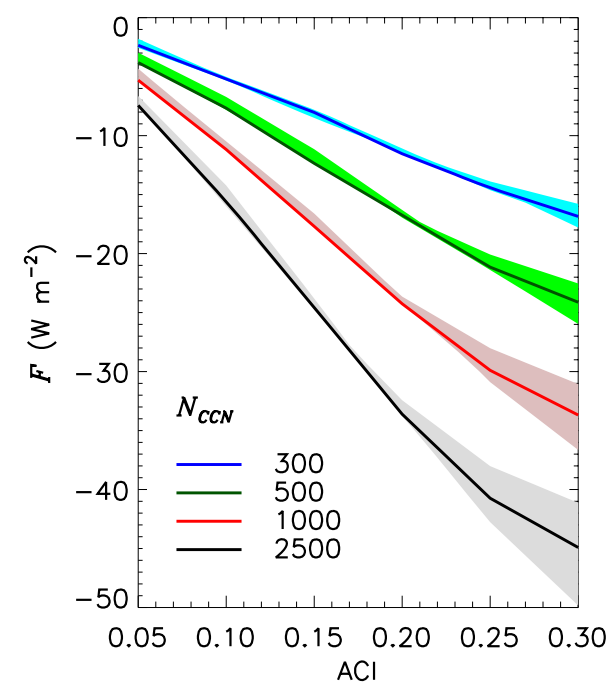

Fig. 2. The amount of forcing as $\mathrm{ACI}_{\tau}$ varies across the observed range in Fig. 1b.Values for forcing are given for the difference of four different $N_{\mathrm{CCN}}$ concentrations from $N_{\mathrm{CCN}}=100 \mathrm{~cm}^{-3}$ and the shaded envelopes represent the range of forcing for each of these concentrations for a range of $L$ from $50-200 \mathrm{~g} \mathrm{~m}^{-2}$.

\subsection{Scale and statistics}

The concept of ecological fallacy gained much attention when Robinson (1950) illustrated that inferring characteristics of relationships among individuals from area-aggregated units did not produce reliable results. Since then, the difficulty in producing reliable statistics from aggregated areal data has been a subject of much concern in fields such as ecology and geography. We will borrow from the field of geography, where the Modifiable Areal Unit Problem (MAUP) (Openshaw, 1984) has been used to describe the effect of level of aggregation (the scale problem) on uni- and multivariate statistics.

It has long been understood that aggregation of data causes biases and error in statistical inferences through its smoothing effect on the data. Signals that occur at scales smaller than the analysis scale will be lost at coarser resolutions. This effect can be visualized very simply using the examples in Fig. 3. The top row (a) provides a simple and contrived example (from Jelinski and $\mathrm{Wu}, 1996$ ) for which the variance $s^{2}$ goes to zero with increased aggregation. The bottom row (b) presents randomly generated numbers between 0 and 1 for which the variance is substantially diminished with aggregation. Note that for aggregation that involves direct averaging of adjacent cells on a regular grid, the mean $\mu$ is unaffected.

The ensuing effects of aggregation by averaging and loss of variance on common calculations of statistics such as the correlation coefficient and regression coefficients, as used in the quantification of aerosol-cloud interactions, are relatively well understood; however, these effects are rarely discussed when inference is made from analyses of ACI at varying 

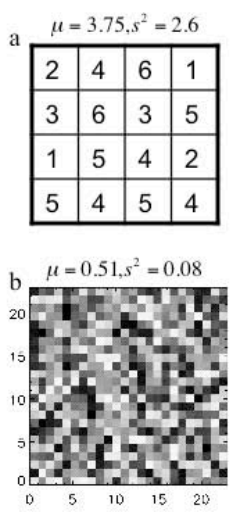

\begin{tabular}{|c|c|}
\hline \multicolumn{2}{|c|}{$\mu=3.75, s^{2}=0.5$} \\
\hline 3 & 3.5 \\
\hline 4.5 & 4 \\
\hline 3 & 3 \\
\hline 4.5 & 4.5 \\
\hline
\end{tabular}

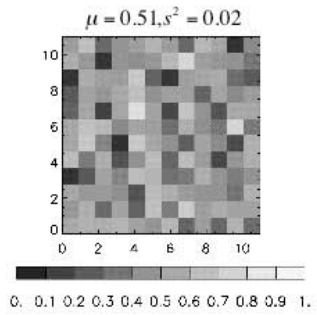

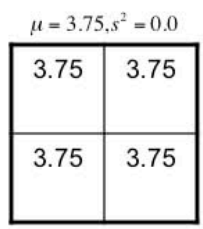

$\mu=0.51, s^{2}=0.01$

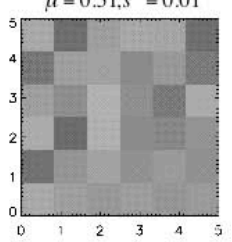

tion) introduces error, while at scales $>1 \mathrm{~km}$, the plane parallel assumption contributes progressively to error in the opposite direction. Without discounting the potential for variability in aerosol, cloud, and radiation to manifest at smaller scales, $1 \mathrm{~km}^{2}$ may represent a reasonable and practical areal unit for study of the problem. This particular scale may hold only for stratiform clouds and is clearly problem-specific.

\subsubsection{Scale and ACI calculations}

Cloud responses to changes in aerosol are typically represented by power-law functions. Using a linear regression between aerosol and cloud properties $y=a+b x$, where $y$ is the logarithm of the cloud property (dependent variable) and $x$ is the logarithm of the aerosol property (independent variable), $\mathrm{ACI}$ is simply an estimator of the regression slope $b$, which can be defined as

$\hat{b}=r_{x y} \frac{s_{y}}{s_{x}}$ or $\mathrm{ACI}=r_{\text {aerosol, cloud }} \frac{s_{\text {cloud }}}{s_{\text {aerosol }}}$.

The correlation coefficient is

$r_{x y}=\frac{\operatorname{COV}(x, y)}{s_{x} s_{y}}$

with $\operatorname{COV}(x y)$ the covariance between and $x$ and $y$ and $s_{x}$ the standard deviation of $n$ samples of variable $x$ with mean $\bar{x}$. The standard deviation of $x$, the square root of the variance $s_{x}^{2}$, is and temporal scales of $2-48 \mathrm{~h}$. For heterogeneous conditions such as smoke plumes near their source, Shinozuka and Redemann (2011) found the relevant scale to be $\sim 1 \mathrm{~km}$. At scales smaller than this, it might be safe to assume that the aerosol adjacent to clouds is a good proxy for that between the clouds (neglecting cloud contamination of the aerosol measurement). The range of $1-400 \mathrm{~km}$ is large, however, and spans the bulk of spatial scales used in studies of ACI (see Fig. 1b)

Typical cloud microphysical scales of variability are much smaller. Fast response instruments show variability in cloud properties down to $\mathrm{cm}$ scales (Brenguier, 1993; Gerber et al., 2001), but considering the scales of motion that drive convection, spatial scales of $10 \mathrm{~m}-100 \mathrm{~m}$ adequately capture bulk cloud properties. These small scales of variability are observable from in situ and ground-based measurements but typically not from space. Wood and Hartmann (2006), using MODIS data at a base resolution of $1 \mathrm{~km}$, found dominant scales of $L$ variability to be between 5 and $50 \mathrm{~km}$, still smaller than the typical analysis scales of $\geq 1^{\circ}$.

The radiative properties of clouds from various regimes contribute to variability dominant at scales of $5 \mathrm{~km}$ and below (e.g., Oreopoulos et al., 2000; Davis et al., 1997). For remote sensing of stratiform boundary layer clouds, the scale at which competing errors associated with the neglect of 3$D$ radiative transfer effects is minimized is $1 \mathrm{~km}$ (Zinner and Mayer, 2006). At scales smaller than $1 \mathrm{~km}$, neglecting horizontal photon transfer (i.e., the independent pixel approxima- $s_{x}=\sqrt{\frac{\sum_{i}(x-\bar{x})^{2}}{n-1}}$.

Hence, changes in ACI with aggregation will be a function of the relative rate of change in the variance of each of the logarithms of aerosol and cloud properties employed, and in the change in covariance between the two. It will be shown that the rate of change in $s^{2}$ with aggregation or scale changes is dependent on the characteristics and the distributions of the properties of interest.

Numerous empirical studies addressing the MAUP have shown that increasing the level of aggregation results in a loss of variance, leading to an increase in $r_{x y}$ (Openshaw, 1984; Fotheringham and Wong, 1991; Amrhein, 1995). In fact, the literature shows that almost any value of $r$ can be obtained for a dataset by averaging to different degrees over space and time. Studies addressing aerosol-cloud interactions have presented $r$ or $r^{2}$ alone or with ACI as evidence of indirect effects, which may be misleading, depending on the level of aggregation of the data considered. Spread in the data may vary depending on whether factors other than aerosol concentration are driving variability in cloud properties. The correlation is not a measure of the causal association between aerosol and cloud properties, only a measure of how completely variations in aerosol affect variations in cloud properties. 
Sekiguchi et al. (2003) provide an example from AVHRR data that are successively averaged in space and time, showing that with aggregation, $r$ increases rapidly (see their Fig. 2). They argue that more highly aggregated data provide a better estimate of the effect due to a higher correlation. While $r$ represents the goodness-of-fit of a linear regression model in this case, it cannot necessarily be used as an indicator of the optimal scale at which to analyze the relationship between aerosol and cloud. We will provide evidence that while disaggregated data may exhibit a wider spread, the fit to these data more accurately represents aerosol-cloud processes and that $r$ or $r^{2}$ should not be used as a criterion for determining the fitness of datasets for quantifying $\mathrm{ACI}$ or the albedo effect.

\subsubsection{Measurements and ACI calculations}

Measurement approach dictates whether data is disaggregated or aggregated and also the degree of aggregation. In any approach to observation, instrument resolution is dependent on limitations generated by integration time and sensor field-of-view. In the case of aerosol or cloud drop concentration, in situ data are generally disaggregated data, as the basic unit of measure is the particle. Temporal resolution is often maximized for in situ observations, within instrumental constraints, as the interest is typically on the microphysical scale. Ground-based and space-based remote sensing produce aggregated data in the form of bulk properties (an average measure of particles, e.g., cloud optical depth) with ground-based data having the potential for much finer resolution. Point-based remote sensing from the ground at high temporal resolution can capture changes in the microphysical and optical properties at a scale that resolves the processes of interest and thus may be considered a proxy for disaggregated data. For satellite-based sensors, the basic areal unit of study, the pixel, tends to be arbitrary relative to the process being studied, and is based rather on general optimization of the sensor. For each of these types of observation, the basic units of measure are "modifiable" through the use of statistical methods for upscaling or aggregation of the data. This is often the case with operational products where retrievals require some amount of averaging or with global coverage products that are much more reasonably distributed and examined at coarser resolutions.

Progressively increasing the level of aggregation of data by averaging carries a number of consequences. The heterogeneity in either the aerosol or cloud microphysical variable internal to the sampling unit is lost at coarser scales. Averaging to larger scales also progressively increases the likelihood of contribution of the multiple (liquid) cloud processes (activation, condensation, entrainmentmixing, collision-coalescence, sedimentation, scavenging), making it less and less relevant to the albedo effect. Thus, the quantification of ACI (constrained by $L$ ) from disaggregated data, regardless of their spread, will be more accurate because measurements were made at the scale of the process and for well-defined conditions. Confidence in that measure should be evaluated by a statistical significance test (p-value) of the regression, regardless of the correlation coefficient, although the two are generally related.

While the use of disaggregated data provides the most accurate representation of the process, we wish to implement this knowledge at the global scale, for which the required fine resolution of either observations or models is not feasible, and for which the operational products from satellite sensors are convenient. Below, we provide some illustrations of the impact of scale on quantifying the albedo effect that address the above dilemma. If we are to exploit data over a wide range of scales, from in situ to global coverage using satellite-based sensors, an understanding of the associated errors is required. The following discussion is intended to illuminate the primary causes of those errors.

\section{Methods}

To illustrate the potential effects of aggregation on the statistical properties of data, we use a range of data sources over the northeast Pacific Ocean. Our data sources are associated with the marine stratocumulus cloud regime, and derive from the Dynamics and Chemistry of Marine Stratocumulus Phase II (DYCOMS-II) experiment (Stevens et al., 2003), which took place off the coast of southern California in July of 2001, as well as the Department of Energy (DOE) deployment to the northern coast of California in 2005. We draw from cloud-resolving model output, ground-based in situ and remote sensing, and satellite-based remote sensing products of aerosol and cloud properties from the Moderate Resolution Imaging Spectroradiomenter (MODIS) sensor aboard the Terra satellite. A description of the various data sources and pertinent information follows.

\subsection{Disaggregated data: Pt. Reyes surface observations}

High-resolution surface observations are used as a proxy for disaggregated data as previously indicated. Measurements of aerosol and cloud properties are taken from the DOE deployment of the Atmospheric Radiation Measurement (ARM) Mobile Facility to Pt. Reyes, CA that ran from March to September of 2005. Near-continuous in situ observations of aerosol and cloud properties as well as radiometer observations of $L$ are available along with daytime observations of $\tau_{\mathrm{c}}$ at a temporal resolution of $20 \mathrm{~s}$. These data are used to produce daily, high temporal resolution correlation statistics between aerosol and cloud properties.

\subsection{Aggregated data: MODIS}

MODIS collection 5 scenes from the Terra satellite from 20 July 2001, during the DYCOMS II experiment, are used as examples of aggregated data. The scenes are located just off 
the California coast over the DYCOMS-II operating region and extend over a larger area of the northeast Pacific. We use Level 2 (L2) data, which provides instantaneous cloud properties at $1 \mathrm{~km}$ (Platnick et al., 2003) and aerosol properties at $10 \mathrm{~km}$ resolution (Remer et al., 2005), as well as daily averaged Level 3 (L3) global coverage data at $1^{\circ}$ resolution.

\subsection{Cloud-resolving model output}

Model output is especially useful for exploring scale effects on quantifying aerosol-cloud interactions since, unlike most observations, co-located variables required for the calculations are present in each grid cell and at each time step. We use model output from the Weather and Research Forecasting (WRF) model run in cloud-resolving mode (Wang and Feingold, 2009) to illustrate the effects of data aggregation on ACI. The WRF model was implemented using environmental parameters from the DYCOMS-II experiment. Simulations were made on $300 \mathrm{~m}$ (horizontal) $\times 30 \mathrm{~m}$ (vertical) grids over a $60 \times 60 \mathrm{~km}$ domain with a time step of three seconds. Snapshots of model output are examined at $15 \mathrm{~min}$ intervals. Cloud optical depth $\tau_{\mathrm{c}}$ from the native WRF runs are shown in the top row of Fig. 4. The three separate instances (a, b, and c) represent different aerosol concentrations $N_{\mathrm{a}}$ and temporal evolutions $t$ as follows: (a) $N_{\mathrm{a}}=500 \mathrm{~cm}^{-3}, t=3 \mathrm{~h}$, (b) $N_{\mathrm{a}}=500 \mathrm{~cm}^{-3}, t=6 \mathrm{~h}$, (c) $N_{\mathrm{a}}=150 \mathrm{~cm}^{-3}, t=9 \mathrm{~h}$. These different instances result in cloud fields in various stages of open and closed cell development with distinct patterns and distributions of cloud properties.

\subsection{PDF sampling for ACI estimation}

The WRF model simulations were all initialized with a constant $N_{\mathrm{a}}$ across the domain so that they exhibit little spatial and temporal variability, except in strongly precipitating conditions. However, in order to calculate correlations between cloud and aerosol properties, as well as ACI, a range of $N_{\mathrm{a}}$ must be present. To achieve this, we ignore the $N_{\mathrm{a}}$ used to generate the simulations and instead use a randomly generated normal distribution of $N_{\mathrm{a}}$ with a mean at the initial modeled $N_{\mathrm{a}}$. Although aerosol number concentrations are often log-normally distributed (Asmi et al., 2011), a normal distribution is used here to simplify illustration of our method. Next we build a joint $L$ and updraft velocity $w$ distribution using the WRF output. Using a method of random sampling that provides a rigorous sample of the population of the $N_{\mathrm{a}}$ and joint $L ; w$ probability distribution functions (PDF), each set of $N_{\mathrm{a}}, L$ and $w$ is used as input to an adiabatic cloud parcel model (Feingold and Heymsfield, 1992) to produce a proxy data set for $\tau_{\mathrm{c}}, N_{\mathrm{d}}$, and $r_{\mathrm{e}}$. The model produces physically consistent sets of $N_{\mathrm{a}}, L, N_{\mathrm{d}}, r_{\mathrm{e}}$ and $\tau_{\mathrm{c}}$ that can be considered representative of co-located aerosol and cloud properties, constrained by the model physics and frequency distribution of the aerosol and cloud measurements. In the more general case, model physics can be adapted for the cloud regime of interest by including entrainment mixing and other relevant processes. A flowchart representing this method is given in Fig. 5. Since the random generation of $N_{\mathrm{a}}$ distributions and the sampling approach results in slight variations in the value of ACI with each separate realization, averages are taken to achieve a robust estimate of ACI. Each data point in an ACI calculation shown in this study is an average from a set of $n=30$ realizations of the parcel model.

This method of sampling data in conjunction with the use of a process-scale model provides a comprehensive data set of well distributed $N_{\mathrm{a}}, L$, and $\tau_{\mathrm{c}}$ from which to calculate and explore the impacts of aggregation and other data constraints on ACI. Note that application of this methodology does not preserve the original $\tau_{\mathrm{c}}$ PDF in the WRF simulations because a PDF of $N_{\mathrm{a}}$ has been applied to generate the PDF of $\tau_{\mathrm{c}}$; nevertheless, average $\tau_{\mathrm{c}}$ and the shape of the distribution is similar. This does not detract from the results since the illustrative nature of these exercises is key. We will apply this methodology in Sect. 4 and also explore extended applications of this approach in semi-empirical quantifications and model parameterizations of the cloud-albedo effect, in Sect. 5 .

\section{Observational biases in ACI}

WRF model output is used to illustrate the basic effects of aggregation on statistics of cloud microphysical properties. Progressive aggregation of the WRF-derived $\tau_{\mathrm{c}}$ field from the original resolution of $0.3 \mathrm{~km}$ to $6 \mathrm{~km}$ (Fig. 4) results in changes in several basic statistical parameters. Note the different scale bars and decrease in range (the difference between maximum and minimum values of $\tau_{\mathrm{c}}$ ) with each level of aggregation in Fig. 4. The scene $s^{2}$, and $\tau_{\mathrm{c}}$ probability distribution functions PDFs for each of these scenes are provided in Fig. 6. The homogeneity parameter $\gamma=(\mu / s)^{2}$ (Barker, 1996; Wood and Hartman, 2006), where $\mu$ is the mean and $s$ is the standard deviation of $\tau_{\mathrm{c}}$, is included in addition to $s^{2}$ in reference to several other studies that use this parameter.

As expected, the scene variance decreases and homogeneity increases as the level of aggregation increases (Fig. 6). As a result, the PDF becomes narrower and more peaked with progressive aggregation. A narrowing of the PDFs with aggregation occurs in response to the loss of variance, but the degree and level of aggregation at which this occurs is dependent on cloud morphology. For instance, by visual inspection of scene "a" in Fig. 4, it is evident that the cloud cells have a characteristic length scale of $\sim 2-3 \mathrm{~km}$. In scene "c", the characteristic length scale is $\sim 20 \mathrm{~km}$. In Fig. 6, a distinct threshold in $\gamma$ and the PDF for "a" is reached near the characteristic length scale of $2.4 \mathrm{~km}$; a more subtle change in $s^{2}$ also occurs at that scale. For scene "c", no such threshold is evident in Fig. 6 up to an aggregation level of $6 \mathrm{~km}$. Constraints on the domain size of the WRF runs do not permit 

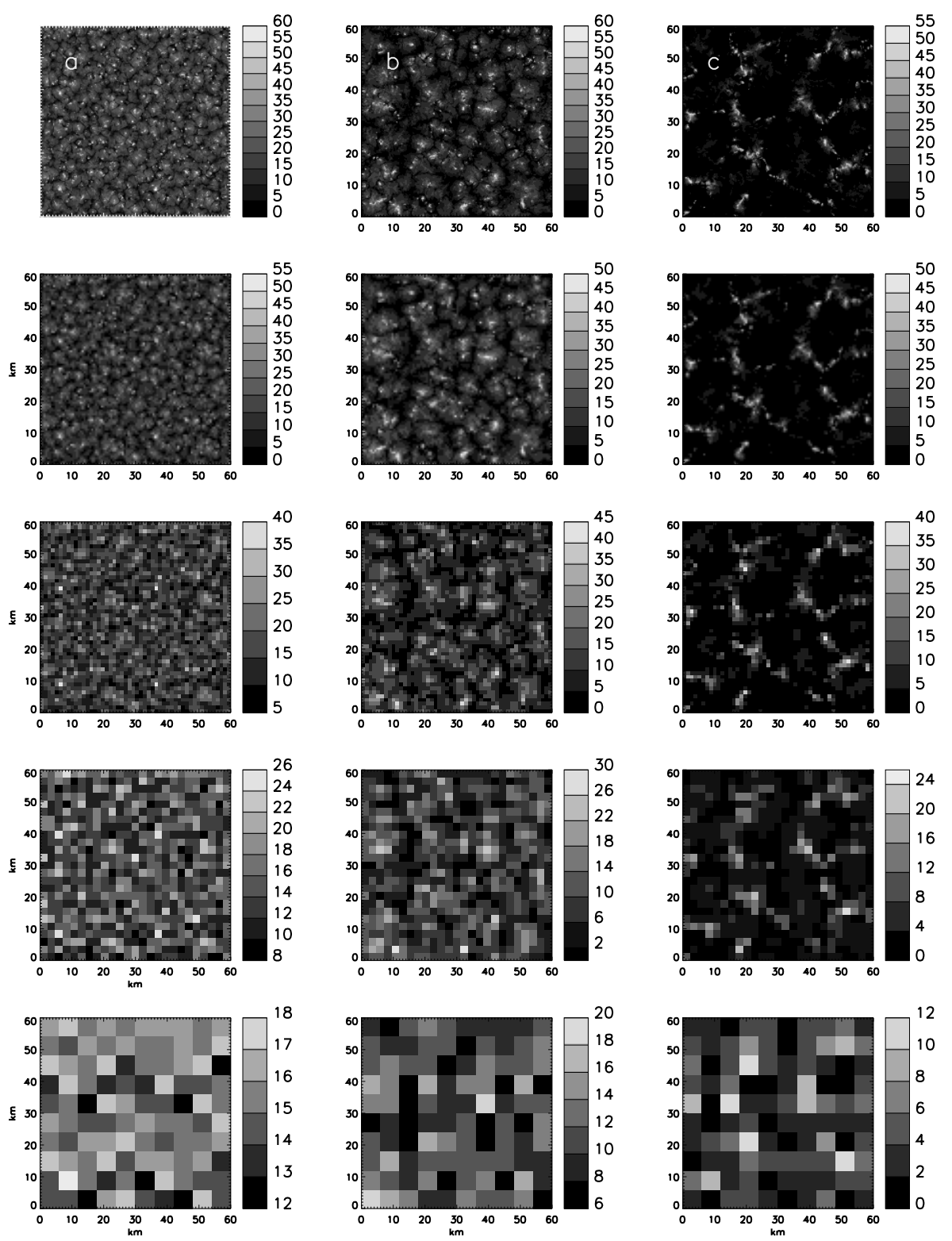

Fig. 4. Modeled $\tau_{\mathrm{c}}$ for three aerosol conditions and stages of temporal evolution: (a) $N_{\mathrm{a}}=500 \mathrm{~cm}^{-3}, t=3 \mathrm{~h}$, (b) $N_{\mathrm{a}}=500 \mathrm{~cm}$, $t=6 \mathrm{~h}$, (c) $N_{\mathrm{a}}=150 \mathrm{~cm}^{-3}, t=9 \mathrm{~h}$. The five levels of aggregation (rows) represent resolutions of $0.3,0.6,1.2,2.4$, and $6 \mathrm{~km}$.

further aggregations. The change in these parameters is nonlinear with scale and different for the three different cloud morphologies in accord with the scale of organization, i.e., characteristic length scales of the cloud features. The specific impacts of variation in organization and cloud field morphology on statistical parameters will be discussed further in the following section.

Figure 7 provides the correlation coefficient between $N_{\mathrm{a}}$ and $\tau_{\mathrm{c}}$ from the PDF sampling outlined in Fig. 5 for data from Fig. 4 and corresponding to the statistics in Fig. 6. The correlation coefficient $r$ shows a dramatic increase with aggregation as expected from previous discussions, with the amount of increase varying with the correlation length scale of cloud features in each of the scenes from Fig. 4a, b, and c. Despite theoretical (Eq. 2) and empirical evidence that aggregation leads to an increase in $r_{x, y}$, which would lead to an increase in the slope parameter, we see the opposite in published values specific to ACI calculations as data sources move from in situ airborne and ground-based remote sensing to satellite studies with increasingly coarse resolutions (Fig. 1b). Why is this the case? It will be shown that two factors specific to the quantification of the albedo effect produce the dampening trend of ACI with decreasing resolution as seen in the literature: (1) the separation between retrieved aerosol and 


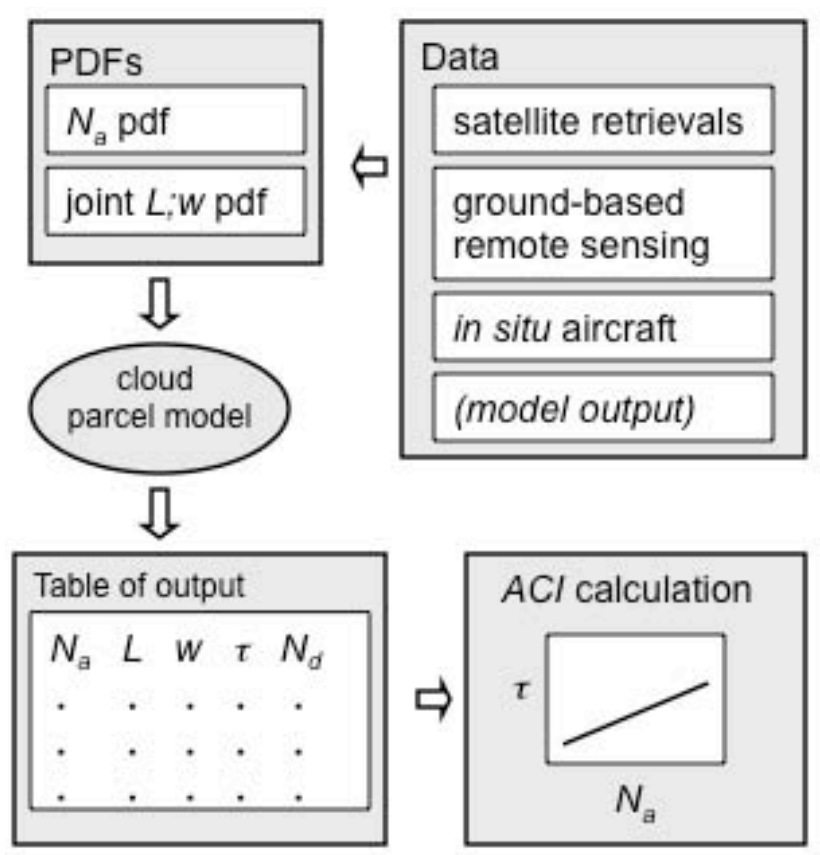

Fig. 5. Flow chart of the random sampling method for an observationally-based approach to ACI calculations. PDFs for input to a process-scale model can be built from a variety of sources including model output and measurements made at a range of scales.

cloud properties in horizontal space in passive satellite remote sensing products and (2) the lack of constraint on $L$ when performing ACI calculations. The latter will be explored with WRF model output whereas the former requires analysis of ground-based and satellite remote sensing data to address the relevant spatial scales of separation.

\subsection{Separation in horizontal space between aerosol and cloud properties}

The problem of spatial separation between aerosol and cloud fields is particular to passive, satellite remote sensing. In the case of airborne field campaigns one can measure nearcoincident in situ aerosol and cloud microphysical properties (e.g., Twomey, 1974; Twohy et al., 2005 and references therein) or use stacked aircraft to assess the cloud albedo effect by measuring reflectance in a single column (Brenguier et al., 2003b; Roberts et al., 2008). Measurements of aerosolcloud interactions using ground-based remote sensing provide high temporal resolution (order $20 \mathrm{~s}$ ), co-located data for aerosol and cloud properties in a single column of air (e.g., Feingold et al., 2003; Kim et al., 2008) and improve confidence that the aerosol measured is that with the potential to impact the cloud properties measured. Ground-based remote sensing and airborne in situ samples are, however, limited in spatial coverage.
Space-based passive remote sensors provide a global perspective of aerosol-cloud interactions, but co-located retrievals of aerosol and cloud properties from these sensors are not physically possible. For the examination of aerosolcloud interactions, an assumption is made that the aerosol is sufficiently homogeneous such that measurements made between clouds are representative of the aerosol feeding into the cloud from below. Even with this assumption, there is potential for aerosol measurements between clouds to be contaminated by humidification, cloud fragments, and enhanced photon scattering (see e.g., discussion in Koren et al., 2009), although these issues are not addressed here. When separated in space or time, the relationship between the measured aerosol concentration and resulting cloud microphysics are likely less representative of the causal relationships that drive the albedo effect and that ACI is intended to quantify.

The effect of separation between individual observations of retrieved aerosol and cloud properties on a fine scale can be easily visualized with high temporal resolution groundbased remote sensing data taken from the ARM Mobile Facility, Pt. Reyes deployment. The data in Fig. 8 is representative of the same cloud regime used to initialize the WRF model simulations employed in this study, thus the cloud characteristics are very similar. $N_{\mathrm{d}}$ was calculated from $\tau_{\mathrm{c}}$ and $L$ (e.g., Bennartz, 2007) originally sampled at $20 \mathrm{~s}$ while $N_{\mathrm{CCN}}$, assumed to vary more slowly, was originally sampled at $30 \mathrm{~min}$ and then resampled to match the sampling frequency of $N_{\mathrm{d}}$. To investigate the effect of separation, we apply increasing lag times between aerosol and cloud data and calculate the cross-correlation. The correlation between $N_{\mathrm{d}}$ and $N_{\mathrm{CCN}}$ at zero lag time is $r=0.38$; at a lag time of 5 $\min \left(1.5-3 \mathrm{~km}\right.$ for an advection velocity of $\left.5-10 \mathrm{~ms}^{-1}\right)$ there is almost no loss in correlation. It is reduced by nearly half (to $r=0.18$ ) over a period of $30 \mathrm{~min}$, or over a distance of $10-20 \mathrm{~km}$, and is near zero after a lag time of $60 \mathrm{~min}$.

The L2 MODIS scene in Fig. 9 illustrates the separation between aerosol optical depth and cloud optical depth that might influence a global analysis of the albedo effect. In the upper left corner of the scene, thin cloud transitions to thicker cloud toward the lower right. There is no information on aerosol variability and its potential contribution to cloud variability. It is clear that in this dataset the aerosol properties are not complete with respect to the location of cloud to meet the criteria of a process-scale analysis. While MODIS L2 data provide instantaneous properties with nearglobal coverage, they are generally not used in global-scale analyses due to the enormous volume of data that would be required. In Sect. 5 we propose the use of MODIS L2 data for regional to global analyses of the albedo effect, capitalizing on the variability in aerosol and cloud properties captured in this higher resolution data.

More often, L3 daily averaged data produced on a regular, $1^{\circ} \times 1^{\circ}$ grid are used for these analyses with a loss in the degree of variability inherent to the L2 data. With passive satellite remote sensing, where aerosol and cloud cannot be 

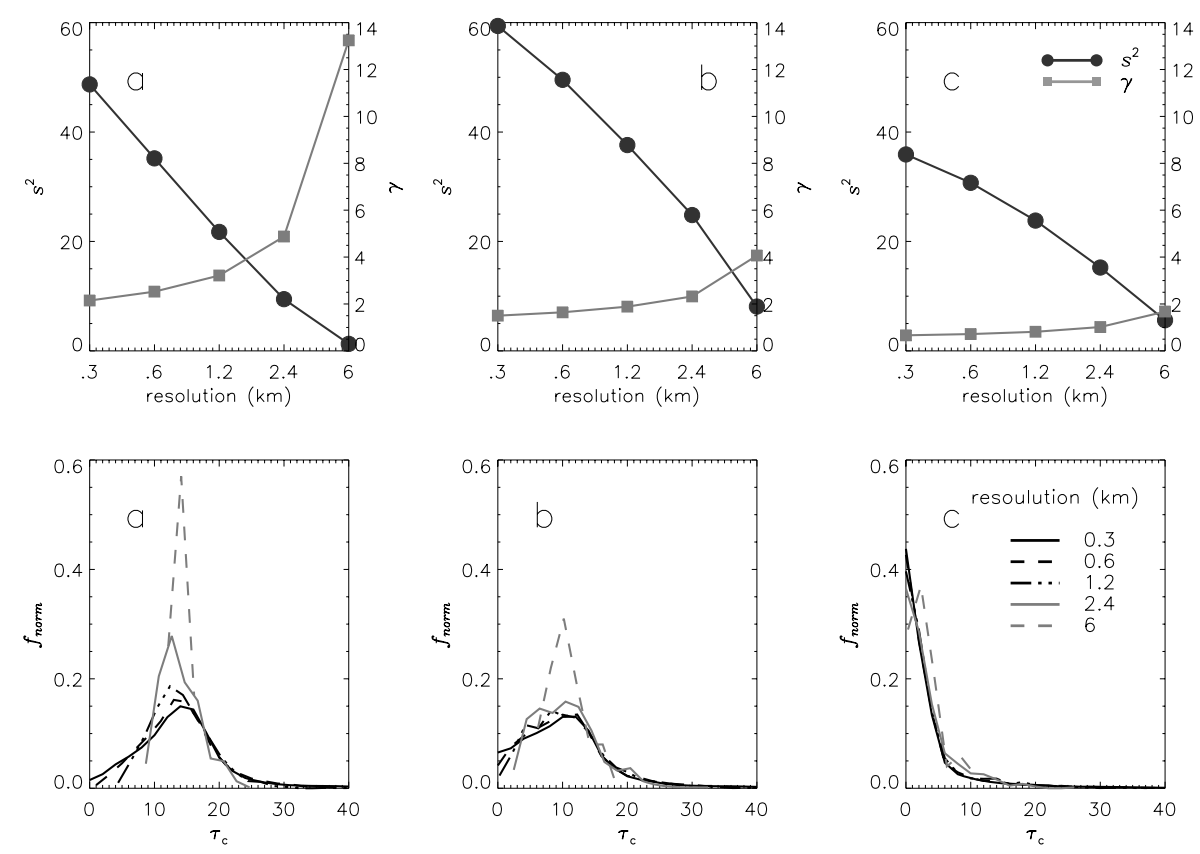

Fig. 6. Statistical parameters variance $s^{2}$, homogeneity parameter $\gamma$, and normalized PDFs of $\tau_{\mathrm{c}}$ for the native resolution and aggregated scenes "a", "b", and "c" in Fig. 4.
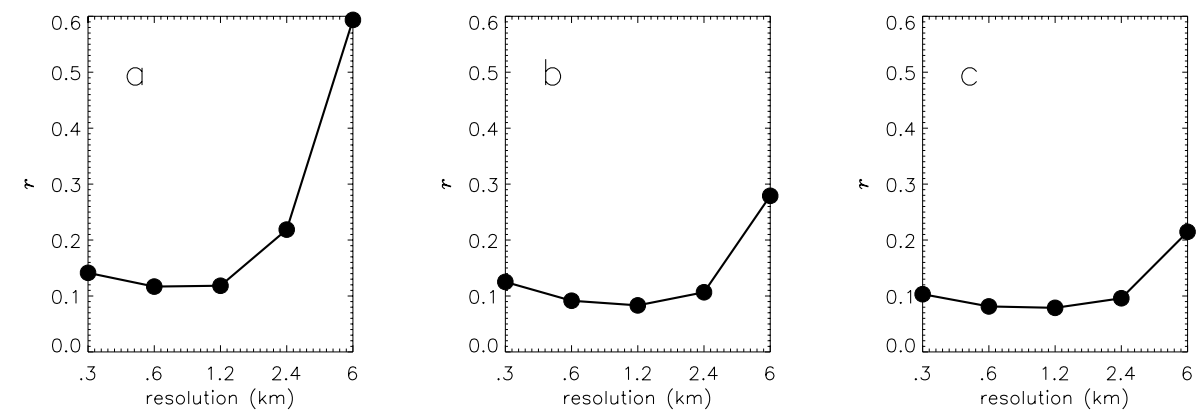

Fig. 7. Statistical parameter $r$ for $\tau_{\mathrm{c}}$ vs. $N_{\mathrm{a}}$ for the native resolution and aggregated scenes from "a", "b", and "c" in Fig. 4.

measured simultaneously, aggregation of aerosol and cloud properties over larger areas (time periods) allows for the population of geographic locations (times) with measured values, where previously values were missing. This provides colocated properties where they may not have existed at finer resolution. However, this computational aggregation may not preserve statistical accuracy in the variables.

This phenomenon can be observed in the MODIS L3 image insets in Fig. 10 that represent the same area of the scenes in Fig. 9 with the same color scales (but different map projections). Note that L3 statistics may not be a function of straightforward averaging of L2 data in space for various reasons. Daily averaged values may result from more than one overpass depending on geographical location (latitude) (Hubanks et al., 2008) and, for 8-day or monthly L3 products, sampling issues caused by the satellite orbital geom- etry, limitations of the retrieval algorithm, and consequent weighting strategies may have a non-negligible impact (Levy et al., 2009). Table 2 provides statistics for this scene at the original (L2) and averaged (L3) resolutions. The percent of co-located aerosol and cloud optical depths increase greatly from 0 in the L2 data (by definition) to $99 \%$ in the L3 data (or $47 \%$ including the swath of missing data in the aerosol optical depth product due to sunglint) but the values also change, becoming more homogeneous. With averaging, the range and variance of the $\tau_{\mathrm{c}}$ data decreases but the range of $\tau_{\mathrm{a}}$ remains constant which, according to Eq. (2), may impact the relationship between aerosol and cloud in a regression analysis.

The extent to which separation error degrades the quantification of aerosol-cloud interactions depends on the heterogeneity of the aerosol and cloud property distribution in 

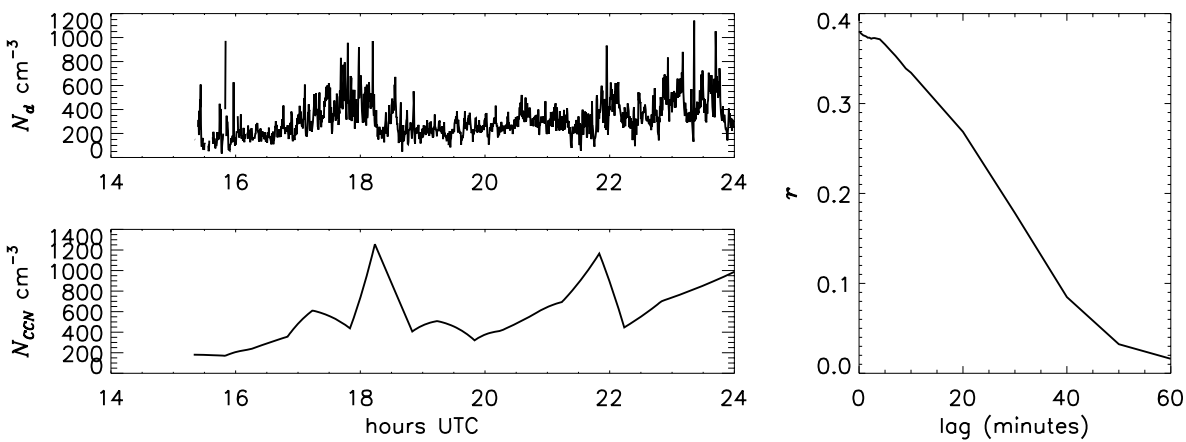

Fig. 8. $N_{\mathrm{d}}, N_{\mathrm{CCN}}$, and their lagged cross-correlation from the DOE Pt. Reyes ARM Mobile Facility deployment in 2005.
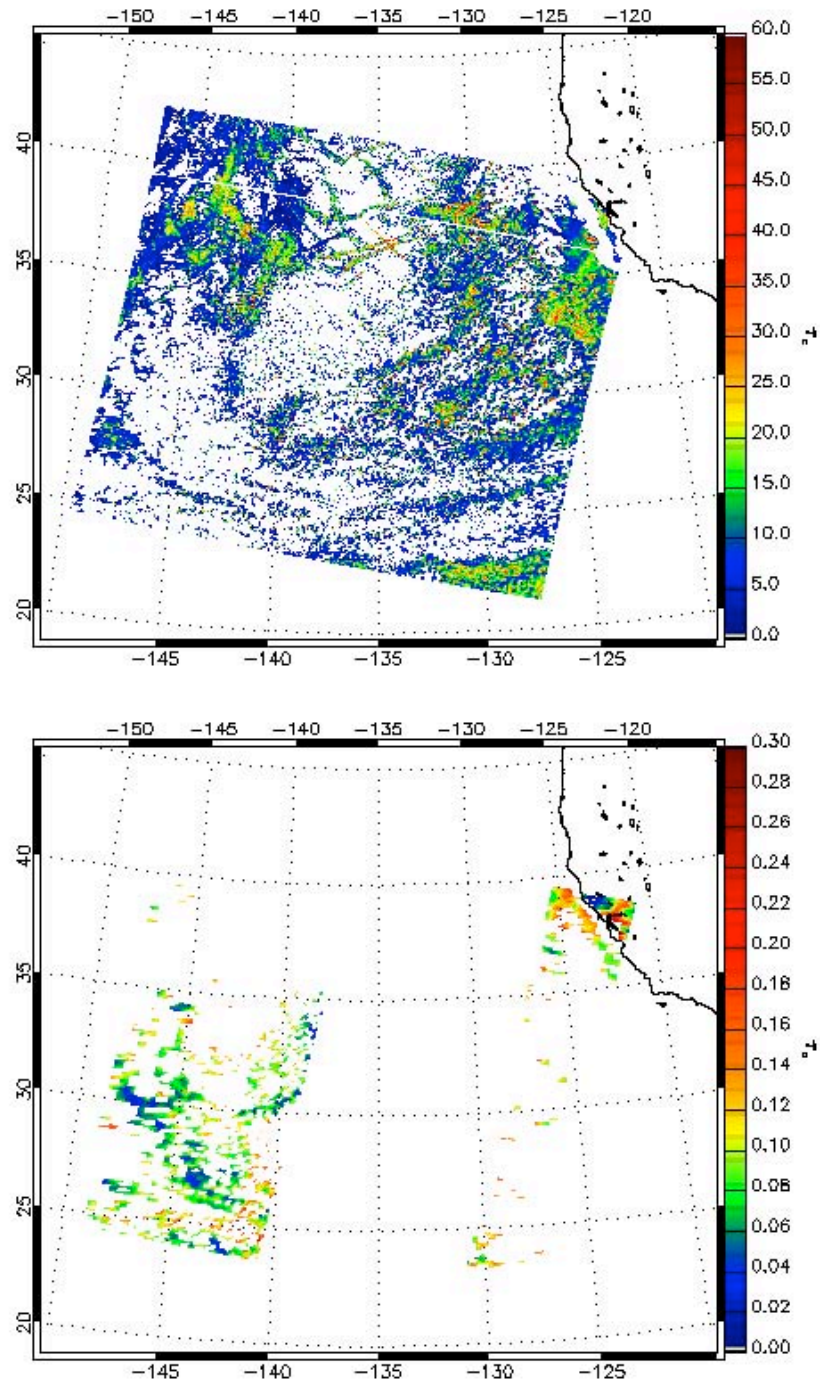

Fig. 9. MODIS Level 2 data over the northeast Pacific Ocean on 20 July 2001: cloud optical depth (top) at $1 \mathrm{~km}$ resolution and aerosol optical depth (bottom) at $10 \mathrm{~km}$ resolution.
Table 2. Statistics for $\tau_{c}$ and $\tau_{\mathrm{a}}$ MODIS L2 and L3 data for the region in Fig. 8 and the box and inset region in Fig. 9.

\begin{tabular}{llllllll}
\hline & & $\min$ & $\max$ & $\mu$ & $\mathrm{s}^{2}$ & \#obs & colocation \\
\hline \multirow{2}{*}{$\tau_{\mathrm{c}}$} & L2 & 0.01 & 61 & 8.5 & 44 & $1,444,271$ & $0 \%$ \\
& L3 & 2.80 & 20 & 9.0 & 9 & 478 & $99 \%^{*}(47 \%)^{* *}$ \\
\hline \multirow{2}{*}{$\tau_{\mathrm{a}}$} & L2 & 0.01 & 0.3 & 0.07 & 0.001 & 3599 & \\
& L3 & 0.02 & 0.3 & 0.08 & 0.001 & 227 & \\
\hline
\end{tabular}

* for the area outside the swath of missing data in the aerosol optical depth scene due to sunglint.

** for the entire scene including the area of missing data due to sunglint.

space. The amount of separation between individual, retrievable aerosol and cloud observations in any given analysis using passive remote sensors will depend on cloud fraction and so the error will, again, be dependent on cloud regime. Commonly, stratiform clouds have been targeted for airborne and ground-based studies of the albedo effect not only for their continuous cover and amenability to sampling, but also for their importance in global radiative forcing and climate sensitivity. These clouds provide conditions for more accurate analyses from ground-based and in situ observations but, because of their high cloud fraction, stratiform clouds would produce the largest biases in satellite analyses due to separation. Grandey and Stier (2010) found that errors in quantifying the albedo effect from space were most notable in stratocumulus regions due to variation of aerosol and cloud properties over regions of analysis spanning scales from $1^{\circ} \times 1^{\circ}$ to $60^{\circ} \times 60^{\circ}$. This spatial variation of properties combined with the inability to sample sufficiently due to high cloud coverage leads to separation and the potential for relatively large errors for this cloud regime when quantified from space. Generally, separation will tend to decrease the value of the correlation coefficient between aerosol and cloud properties, which will decrease ACI. When aggregation is used to improve the frequency of co-located aerosol and cloud properties the effect on ACI may be variable and depend on the individual set of distributions. 

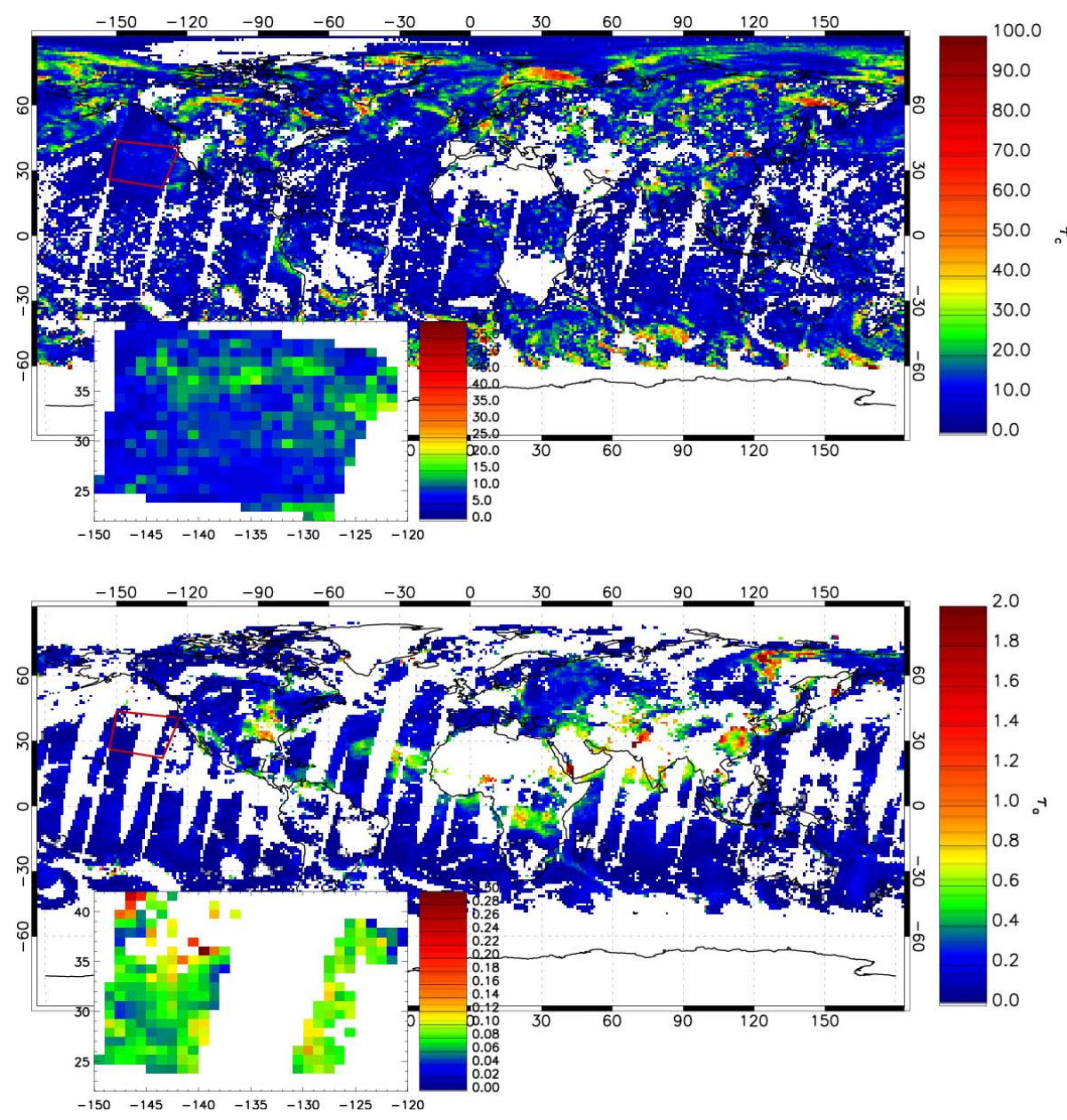

Fig. 10. MODIS Level 3 global data on 20 July 2001: cloud optical depth (top) and aerosol optical depth (bottom), both at $1^{\circ}$ resolution. The insets represent the same area as the scenes in Fig. 9 over the northeast Pacific Ocean and have the same color scales.

\subsection{Ignoring the constraint on cloud liquid water path}

Cloud optical depth and reflectance are highly correlated with $L$ (Schwartz et al., 2002; Kim et al., 2003). Various factors including meteorology and cloud drop microphysical properties can result in variability in $\tau_{\mathrm{c}}$. By constraining changes in $\tau_{\mathrm{c}}$ by $L$, the remaining variability will be due primarily to changes in microphysical properties associated with variation in aerosol. Without this constraint, larger-scale meteorological processes that produce variability in $L$ and therefore $\tau_{\mathrm{c}}$ will confound detection of aerosol-cloud interactions associated with the albedo effect.

When calculating ACI, the constraint on $L$ is often ignored in satellite-based analyses due the difficulty in achieving an independent measure of $L$ coincident with other cloud and aerosol properties. When unconstrained, the regression slope is often flattened due to the spread of uncorrelated aerosol and cloud parameters across different $L$ values that exist in varied meteorological conditions. This was shown using ground-based observations from Pt. Reyes (McComiskey et al., 2009). Here, the PDF sampling methodology described in Sect. 3.4 and outlined in Fig. 5 is applied to WRF model output to illustrate the impact of ignoring the constraint on $L$ when quantifying ACI and to show the robustness of this result.

Figure 11 represents all of the data points from scene "b" in Fig. 4 at its native (highest) resolution. Each variable ( $N_{\mathrm{a}}$ and $\tau_{\mathrm{c}}$ ) is grouped based on $10 \mathrm{~g} \mathrm{~m}^{-2} L$ bins to provide the required constraint. Independent calculations of ACI are made using the $N_{\mathrm{a}}$ and $\tau_{\mathrm{c}}$ data from each bin and then these values are averaged (weighted by the numbers of points in each bin) to provide a single ACI value for the scene. The colored symbols represent a sample of those bins. The unconstrained ACI is also calculated for the full set of data in the scene, represented by the grey symbols and the black line. The unconstrained ACI value of 0.16 is lower than any of the constrained values of $0.22,0.26$, and 0.32 . The averaged, constrained ACI is 0.22 . The correlation coefficient that corresponds to this set of data is 0.13 (see Fig. $7 \mathrm{~b}, 0.3 \mathrm{~km}$ resolution). 


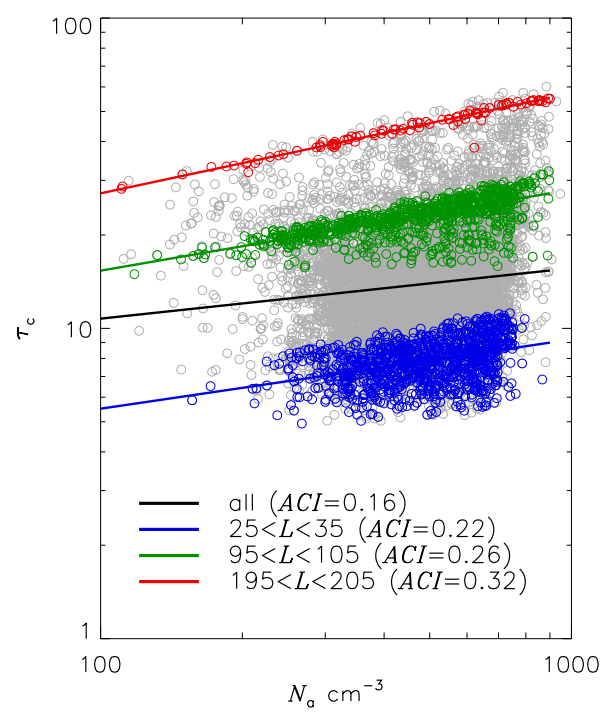

Fig. 11. Pairs of $N_{\mathrm{a}}$ and $\tau_{\mathrm{c}}$ produced by a parcel model following the PDF sampling method in Fig. 5 using aerosol and cloud property inputs derived from the high resolution case of WRF scene " $b$ " in Fig. 4. Grey symbols represent all data points from the modeled scene and colored symbols represent selected $10 \mathrm{~g} \mathrm{~m}^{-2} L$ bins. The black line represents the unconstrained slope or ACI resulting from all data points and the colored lines represent the slopes for that $L$ bin, or selected constrained ACI values.

Plane parallel radiative transfer calculations following McComiskey and Feingold (2008) shown in Fig. 2 indicate that the difference in constrained versus unconstrained ACI would result in a difference in local ( $100 \%$ cloud cover) radiative forcing of the cloud albedo effect of approximately $3 \mathrm{~W} \mathrm{~m}^{-2}$ (given a change in CCN from 100 to $300 \mathrm{~cm}^{-3}$, $L=125 \mathrm{~g} \mathrm{~m}^{-2}$ ) or approximately $0.75 \mathrm{~W} \mathrm{~m}^{-2}$ for a globe with a $25 \%$ liquid water cloud fraction, discounting 3-D radiative transfer effects. This is a potentially important source of bias in observationally based radiative forcing estimates of the albedo effect.

With progressive aggregation of data, the result above holds until the statistical properties of the cloud and aerosol data become too smooth to allow for a valid ACI calculation. Figure 12 shows the constrained and unconstrained ACI values at each level of aggregation for the three scenes in Fig. 4 (top row). A distinct feature is that the difference between constrained and unconstrained ACI values increases as the heterogeneity within the cloud field increases (Fig. 4, top row) from the relatively homogeneous case of closed cells in scene "a" to the open cell, heterogeneous scene "c". This is clearly an effect of the increasingly disparate values of $L$ within each scene. The small difference between constrained and unconstrained ACI values in scene "a" for the highest level of aggregation is consistent with the high homogeneity parameter for this case (Fig. 6).

The amount of bias that cloud field heterogeneity produces in quantifying the albedo effect is based on the analysis scale and heterogeneity of the measured property internal to that unit of observation. In a homogeneous scene, aggregation of properties results in a relatively accurate representation of the finer-scale properties and processes. However, as organization and pattern become more distinct and complex, aggregation will cause loss of information associated with that pattern. At increasingly larger scales, global studies using satellite-based observations lump together various cloud types with widely varying patterns, as well as aerosol with varying properties (Grandey and Stier, 2010). In such cases, the trend of increasing differences between ACI constrained and unconstrained by $L$ with scene heterogeneity could result in unconstrained ACI values that are biased very low, such as the analyses that fall to the right of the plot in Fig. $1 \mathrm{~b}$ with resolutions on the order of $4^{\circ}$.

Figure 12 shows that the unconstrained values of ACI are less than the constrained values in all but a couple of cases. With increasing aggregation, the values of ACI generally follow the trends of the statistics presented in Fig. 6, manifesting some effects of the characteristic length scales of the cloud properties. Distinct increases occur at the highest level of aggregation. In this example, larger ACI values are typically a function of narrow distributions that result from aggregation, similar to the narrowing of the $\tau_{\mathrm{c}}$ PDFs in Fig. 6. Similar results were found for the ground-based data from Pt. Reyes in which the days that had naturally low variability in aerosol concentrations did not provide useful ACI values because distributions were too narrow to achieve a meaningful regression slope (McComiskey et al., 2009). Here we see that the same result can occur from artificially narrowing distributions through aggregation. Generally, this affects data sets in which sample numbers are limited, a problem not encountered in global analyses.

Looking into the individual realizations that make up the ACI values in Fig. 12 provides valuable information for understanding the issues associated with calculating ACI with less-than-ideal data sets. Figure 13 contains the individual ACI calculations (based on Sect. 3.4) from the scene in Fig. 4c, top row for the constrained and unconstrained values at the finest $(0.3 \mathrm{~km})$ and coarsest $(6 \mathrm{~km})$ resolutions. The set of realizations is stable for both the constrained and unconstrained calculations at $0.3 \mathrm{~km}$ resolution and fall within the physically meaningful limits of the relationship (Eq. 1a) between 0 and 0.33 . With substantial aggregation to $6 \mathrm{~km}$, spurious values of ACI appear for both constrained and unconstrained calculations, but more so for the unconstrained calculations. This is due to the fact that aggregation results in fewer data points from which to calculate a regression slope, resulting in an ACI value that is not robust.

In general, this exercise has shown that unconstrained ACI values tend to be lower than properly calculated, constrained values. While the use of unconstrained values is not appropriate for quantifying the albedo effect, the relationships may have a different but equally physically useful meaning. The relationships between aerosol and cloud properties derived 

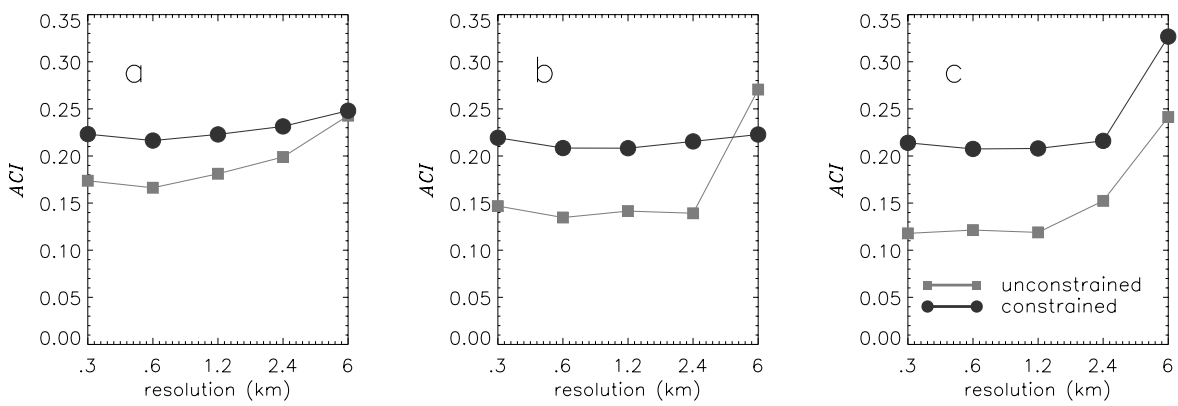

Fig. 12. Unconstrained and constrained ACI with change in level of aggregation for scenes "a", "b", and "c" in Fig. 4 (top row).

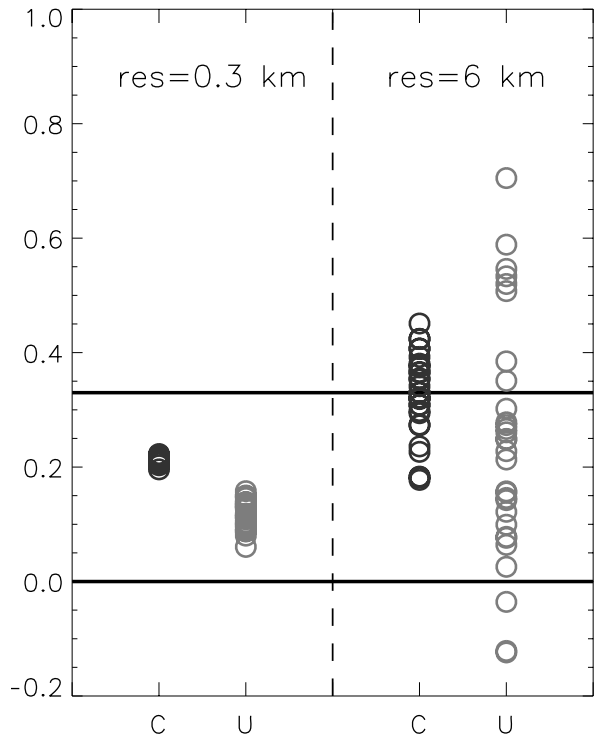

Fig. 13. Constrained (C) and unconstrained (U) ACI for the finest and coarsest resolutions of scene "c" from Fig. 4. Each set of constrained and unconstrained values consists of 30 data points. The horizontal lines at $\mathrm{ACI}=0$ and 0.33 mark the physical limits of the relationship.

without constraint on $L$ are ipso facto more representative of the full system of aerosol-cloud processes in rapid adjustment rather than just the albedo effect. Hence, the range of radiative forcing from observational estimates shown in Fig. 1a (at right), excluding those constrained observations made at the process scale, may also be more representative of the multitude of aerosol-cloud interactions with feedbacks rather than solely the albedo effect. Considering ACI estimates from satellite only at a scale of $1^{\circ}$ and larger, that range in forcing, under the same conditions of the calculations in Sect. 2 (factor of 3 increase in $N_{\mathrm{CCN}}$ and a global average liquid water cloud cover of $25 \%$ with mean $L=125 \mathrm{~g} \mathrm{~m}^{-2}$ ) becomes -0.2 to $-1.5 \mathrm{~W} \mathrm{~m}^{-2}$.

\section{Observationally-based measurement of ACI using regime-dependent PDFs}

We have shown that for processes such as the albedo effect that operate on the microphysical scale, the use of aggregated data results in errors of statistics and sampling, leading to biases in associated radiative forcing estimates. Additionally, lack of constraints on the analysis, common with the use of aggregated data, often results in a low bias. However, disaggregated data does not easily lend itself to global coverage and, for regional-to-global scale studies that can address climate issues, data must be scaled-up in a manner that preserves the inherent processes. An approach to an observationally-based estimate of the albedo effect that uses data in conjunction with a process model was outlined previously (Sect. 3.4; Fig. 5) and applied to WRF model output in Figs. 11, 12, and 13. It is detailed here in the context of employing observational data rather than the WRF model output. The objective is to devise an observationally-based approach to radiative forcing estimates and to reduce climate model uncertainty or biases in those estimates. This proposed approach preserves the internal heterogeneity of units of observation through the use of PDFs rather than means.

The methodology is expanded upon here with the illustrative example of a non-precipitating cloud with relatively small influence of drop coalescence processes and related feedbacks such as wet removal of aerosol. To calculate ACI we require PDFs of $L$ (preferably joint with $w$; see below) and a measure of aerosol concentration $N_{\mathrm{a}}$. An independent measure of $L$ is desirable, provided it is at a matched scale. The PDFs are randomly sampled for sets of $L ; w$ and $N_{\mathrm{a}}$, which are then used as input to a cloud parcel model (or parameterization thereof). This yields an associated PDF of $\tau_{\mathrm{c}}$ or a proxy $\left(N_{\mathrm{d}}\right.$ or $\left.r_{\mathrm{e}}\right)$ that represents the detailed physical processes involved in microphysical-scale aerosol-cloud interactions. The model must ensure that processes relevant to drop activation are well represented. The physics included in the model could vary by regime, depending, for example, on cloud type, adiabatic liquid water fraction, and/or aerosol composition. Although for simplicity we have presented this approach with an adiabatic model, it could easily be extended 
to include sub-adiabaticity using either continuous (e.g., Lee and Pruppacher, 1977) or discrete (Krueger et al., 1997) mixing models.

Note that satellite sensors yield independent measurements of $r_{\mathrm{e}}$ and $\tau_{\mathrm{c}}$, from which $L\left(\propto r_{\mathrm{e}} \times \tau_{\mathrm{c}}\right)$ is derived. The procedure described above is based on a sampling of the PDF of $L$, but the model generates an internally consistent $\tau_{\mathrm{c}}$. An important final stage of this procedure is to ensure that the model-generated frequency distribution of $\tau_{\mathrm{c}}$ conforms, within measurement uncertainties, to the observed $\tau_{\mathrm{c}}$ distribution. Lack of agreement would indicate that the model is not capturing the key cloud processes.

Because of the inherent coupling between $L$ and $w$, the fidelity of the calculations can be increased if the dependence on the joint distributions of $L ; w$ is included, as in Sect. 3. This is especially true under high aerosol loadings where $w$ plays an increasingly important role in influencing the strength of the cloud response to aerosol (Feingold, 2003; McComiskey et al., 2009). Recent efforts combining Doppler radar and microwave radiometer are beginning to produce such PDFs (P. Kollias and E. Luke, personal communication, 2011) but the extent to which these are dependent on cloud regime must be ascertained before they can be applied more generally.

The random sampling of the aerosol and joint $L ; w$ distributions described above represents the full range of possible couplings between aerosol, cloud water, and updraft velocity characteristics over a given domain. This provides "colocated" sets of aerosol, cloud optical depth, and cloud liquid water that span the entire range of likely values in a given regime or geographical location. Sampling these full distributions to calculate ACI would provide results with bounds on the potential strength of the albedo effect (the uncertainty in ACI). Typical distributions for different cloud regimes in different geographical locations will result in characteristic globally and temporally distributed ACI values.

An example of data that could be used with this methodology are PDFs collected over space and time at relatively high spatial resolution, e.g., MODIS L2 data at $1-10 \mathrm{~km}$ as presented in Fig. 9. These provide a representative distribution of the properties that occur at a given location and/or season over the long-term (albeit without vertical velocity) and are, thus, statistically well-constrained. While MODIS L3 data have collated such distributions, the bin designations for some properties are not optimal for this application, especially those for aerosol. Both ground- and spacebased observations including active and passive remote sensing can contribute to building such distributions and can provide added dimensionality to the data (e.g., precipitating vs. non-precipitating conditions; Lebsock et al., 2008).

The attractiveness of this method is that it is applicable to observational and model-generated properties and can potentially be used in observationally-based radiative forcing estimates as described above, as well as model evaluation and possibly empirical model parameterization. For the lat- ter, distributions of aerosol, cloud, and updraft velocity parameters within a model grid cell can be used to designate an appropriate value of ACI. Computationally, this would provide a less expensive method than activation parameterization schemes but a more accurate approach than global single-value ACI-based estimates. Alternatively, the characteristic globally- and seasonally-determined ACI values from the previously described observationally-based analysis could be used in models in place of a single, global value.

\section{Discussion and conclusions}

The influence of aerosol on cloud albedo is recognized as a major unknown. It likely results in planetary cooling, the magnitude of which is poorly constrained. Our contention is that model estimates of the radiative impacts of the albedo effect that are based on observed aerosol-cloud interaction (ACI) metrics are biased due to a mismatch between process and analysis scales. The historic use of a single measure (ACI) based on data from a range of different observational scales and platforms results in widely varying radiative forcing estimates.

Simple numerical aggregation of data to reach a desired geographical scale does not produce the intended, physically meaningful result at that scale. This is readily seen in the literature that addresses the quantification of the microphysical aspect of the albedo effect, as measured here by ACI. The questions raised here extend beyond the albedo effect; the same issues pertain to other metrics of aerosol-cloud interactions such as aerosol-cloud fraction relationships and aerosol impacts on precipitation such as precipitation susceptibility (e.g., Sorooshian et al., 2009). There the problems are even more difficult because, unlike ACI, they are not constrained by simple physical principles (Eq. 1).

Several conclusions relevant to biases in calculating ACI across scales can be drawn from the above illustrations. ACI employed directly in its form presented in Eq. (1) is useful with process-level/small-scale measurements but is not appropriate for quantifying the albedo effect using aggregated/large-scale measurements from passive, spacebased remote sensors, especially in the absence of a constraint on $L$. Ignoring the constraint on $L$ in calculations of ACI for any observational approach produces a dampening of the signal leading to weaker radiative forcing estimates. The magnitude of this bias is dependent on cloud field morphology (cloud regime) and the interaction of the characteristic scale of cloud features and aerosol distributions with the observational or analysis scale. The bias increases with increasing heterogeneity in the cloud scene (i.e., increasing variability in $L$ ). Separation between aerosol and cloud properties in space and/or time results in reduced correlation between the parameters and dampened ACI values. Because of these issues, observed regional-to-global-scale correlations between aerosol and cloud without appropriate constraints on cloud 
liquid water do not accurately represent the microphysicalscale interactions between aerosol and cloud albedo. This results in biases in radiative forcing estimates of the cloudalbedo effect in GCMs.

The examination of Grandey and Stier (2010) into the impacts of scale on quantifying the albedo effect concluded that successive sampling of satellite data from regions of $1^{\circ} \times 1^{\circ}$ to $60^{\circ} \times 60^{\circ}$ resulted in an associated radiative forcing that increased with coarser resolution. This is in contrast to the ACI results we show in Fig. 1b from studies throughout the literature that span a range of scales. They used a derivation of $N_{\mathrm{d}}=f\left(\tau_{\mathrm{c}}\right.$ and $\left.r_{\mathrm{e}}\right)$ from MODIS that should in principle be independent of $L$ and thus their results were not affected by lack of constraint on $L$, but predominately by other aggregation effects as discussed in Sect. 2. Here, we have focused on the biases that are incurred in calculation of ACI using aggregated data, which includes all satellite-based observations, as opposed to disaggregated data, which better represents the local microphysical processes. We find that, in this case, simple aggregation biases are dominated by the effect of separation of aerosol and cloud properties in space and time and the lack of constraint on $L$, resulting in associated radiative forcings that decrease with decreasing resolution. From these two studies it becomes clear that consideration of the scale and approach to quantifying aerosol-cloud interactions is essential, with no simple recipe for doing so.

Alternative approaches to quantifying the albedo effect exist and should be capitalized upon. Alternatives may include the combination of multiple available passive and active space-based sensors with airborne and ground-based measurements, process-scale modeling, and extrapolation of results using disaggregated data to larger-scales. As the errors in these quantifications are related to cloud field morphology, considering these approaches on a regime-dependent basis may help to minimize that error. The use of regimedependent PDFs of aerosol and cloud properties may also lead to progress in observationally-based estimates of the albedo effect as well as datasets that could be used for model evaluation and parameterization. Because it is not currently practical to obtain co-located measures of aerosol and cloud globally, a viable option is to link the needed observations with cloud process models. We have presented a methodology for such a model-based, observationally-constrained assessment of the albedo effect based on sampling of the full range of the PDF of aerosol and the PDF of liquid water path (preferably joint with updraft velocity). The result will be a quantity describing aerosol-cloud interactions that are dictated by model physics (determined by cloud regime) and constrained by observations.

What is the appropriate scale at which to observe and characterize processes related to aerosol-cloud interactions? It is our assertion that to quantify the albedo effect accurately, disaggregated data (in situ measurements) should be used, or data aggregated only up to the scale that heterogeneity in aerosol and cloud properties is preserved within reasonable error bounds (e.g., as provided by ground-based remote sensing). Accurate measures from aggregated data are possible to the extent that they meet these spatial or temporal heterogeneity constraints. A brief survey of scales of variability (Sect. 2.2) indicates that $1 \mathrm{~km}$ may be a reasonable resolution. If these critical scales are not taken into consideration, a heterogeneity- (and therefore geographical- or regime-) dependent bias in ACI will result. Although prior studies have addressed the properties of aerosol and cloud spatial variability, for indirect effects there is the added complexity of assessing the change in covariance properties with the scale of the aerosol and cloud observations. Quantifying length scales of heterogeneity in different cloud regimes to reduce aggregational error in analyses of aerosol-cloud interactions is a non-trivial problem that will require a focused research effort.

Another question that this paper raises is: what does ACI represent? At the core, process level, ACI represents the activation process. At larger scales it must, ipso facto, include other cloud microphysical processes whose contributions vary from one cloud regime to another. To the climate modeler working with grid boxes of order $1^{\circ}$, ACI must therefore also represent the broader spectrum of cloud microphysical processes. However, since the albedo effect only attempts to address instantaneous impacts of aerosol on cloud albedo without the complications of feedbacks to cloud fraction or $L$, it becomes particularly hard to justify continued use of empirical measures of ACI as a means of assessing the albedo effect. Instead, the full range of aerosol effects on cloud microphysics should be addressed using process-scale measures of ACI (e.g., $\sim 1 \mathrm{~km}$ ), unconstrained by $L$, that have been aggregated to the climate model scale. Moreover, if the measures of ACI have been aggregated appropriately, e.g., using the model-based method described in Sect. 5, then they are more likely to embody causality rather than unphysical correlation induced by large-scale averaging.

Acknowledgements. This research was supported by the Office of Science (BER), U.S. Department of Energy, Interagency Agreement No. DE-SC0002037. We thank Hailong Wang for providing the cloud resolving model fields in Fig. 5.

Edited by: J. Quaas

\section{References}

Ackerman, A., Kirkpatrick, M. P., Stevens, D. E., and Toon, O. B.: The impact of humidity above stratiform clouds on indirect aerosol climate forcing, Nature, 432, doi:10.1038/nature03174, 2004.

Albrecht, B.: Aerosols, cloud microphysics, and fractional cloudiness, Science, 245, 1227-1230, 1989.

Amrhein, C. G.: Searching for the elusive aggregation effect: evidence from statistical simulations, Environment and Planning A, 27, 105-119, 1995. 
Anderson, T. L., Charlson, R. J., Winker, D. M., Ogren, J. A., and Holmen, K.: Mesoscale variations of tropospheric aerosols, J. Atmos. Sci., 60, 119-136, 2003.

Asmi, A., Wiedensohler, A., Laj, P., Fjaeraa, A.-M., Sellegri, K., Birmili, W., Weingartner, E., Baltensperger, U., Zdimal, V., Zikova, N., Putaud, J.-P., Marinoni, A., Tunved, P., Hansson, H.C., Fiebig, M., Kivekäs, N., Lihavainen, H., Asmi, E., Ulevicius, V., Aalto, P. P., Swietlicki, E., Kristensson, A., Mihalopoulos, N., Kalivitis, N., Kalapov, I., Kiss, G., de Leeuw, G., Henzing, B., Harrison, R. M., Beddows, D., O’Dowd, C., Jennings, S. G., Flentje, H., Weinhold, K., Meinhardt, F., Ries, L., and Kulmala, M.: Number size distributions and seasonality of submicron particles in Europe 20082009, Atmos. Chem. Phys., 11, 5505-5538, doi:10.5194/acp-11-5505-2011, 2011.

Barker, H.: A Parameterization for Computing Grid-Averaged Solar Fluxes for Inhomogeneous Marine Boundary Layer Clouds. Part I: Methodology and Homogeneous Biases, J. Atmos. Sci., 53, 2289-2303, 1996.

Bennartz, R.: Global assessment of marine boundary layer cloud droplet number concentration from satellite, J. Geophys. Res., 112, D02201, doi:10.1029/2006JD007547, 2007.

Bony, S. and Dufrense, J.-L.: Marine boundary layer clouds at the heart of tropical feedback uncertainties in climate models, Geophys. Res. Lett., 32, L20806, doi:10.1029/2005GL023851, 2005.

Brenguier, J.-L.: Observation of cloud microstructure at the centimeter scale, J. Appl. Meteor., 32, 783-793, 1993.

Brenguier, J.-L., Pawlowska, H., and Schuller, L.: Cloud microphysical and radiative properties for parameterization and satellite monitoring of the indirect effect of aerosol on climate, J. Geophys. Res., 108, 8632, doi:10.1029/2002JD002682, 2003a.

Brenguier, J.-L., Chuang, P. Y., Fouquart, Y., Johnson, D. W., Parol, F., Pawlowska, H., Pelon, J., Schüller, L., Schröder, F., and Snider, J.: An overview of the ACE-2 CLOUDYCOLUMN closure experiment, Tellus B, 52, 815-827, doi:10.1034/j.16000889.2000.00047.x, 2003b.

Bréon, F.-M., Tanre, D., and Generoso, S.: Aerosol Effect on Cloud Droplet Size Monitored from Satellite, Science, 295, 834, doi:10.1126/science.1066434, 2002.

Bulgin, C. E., Palmer, P. I., Thomas, G. E., Arnold, C. P. G., Campmany, E., Carboni, E., Grainger, R. G., Poulsen, C., Siddans, R., and Lawrence, B. N.: Regional and seasonal variations of the Twomey indirect effect as observed by the ATSR-2 satellite instrument, Geophys. Res. Lett., 35, L02811, doi:10.1029/2007GL031394, 2008.

Chameides, W. L., Luo, C., Saylor, R., Streets, D., Huang, Y., Bergin, M., and Giorgi, F: Correlations between modelcalculated anthropogenic aerosols and satellite-derived cloud optical depths: Indication of indirect effect?, J. Geophys. Res, 107, 4085, doi:10.1029/2000JD000208, 2002.

Davis, A., Marshak, A., Cahalan, R., and Wiscombe, W.: The Landsat scale break in stratocumulus as a three-dimensional radiative transfer effect: Implications for cloud remote sensing, J. Atmos. Sci., 54, 241-260, 1997.

Feingold, G.: Modeling of the first indirect effect: Analysis of measurement requirements, Geophys. Res. Lett., 30, 1997, doi:10.1029/2003g1017967, 2003.

Feingold, G. and Heymsfeld, A.: Parameterizations of the condensational growth of droplets for use in GCMs, J. Atmos. Sci. 49, 2325-2342, 1992.
Feingold, G., Remer, L. A., Ramaprasad, J., and Kaufman, Y. J.: Analysis of smoke impact on clouds in Brazilian biomass burning regions: An extension of Twomey's approach, J. Geophys. Res., 106, 22907-22922, 2001.

Feingold, G., Eberhard, W. L., Veron, D. E., and Previdi, M.: First measurements of the Twomey indirect effect using ground-based remote sensors, Geophys. Res. Lett., 30, 1287, doi:10.1029/2002GL016633, 2003.

Forster, P., Ramaswamy, V., Artaxo, P., Berntsen, T., Betts, R., Fahey, D. W., Haywood, J., Lean, J., Lowe, D. C., Myhre, G., Nganga, J., Prinn, R., Raga, G., Schulz, M., and Van Dorland, R.: Changes in atmospheric constituents and in radiative forcing, in Climate Change 2007: The Physical Science Basis - Contribution of Working Group I to the Fourth Assessment Report of the Intergovernmental Panel on Climate Change, edited by: Solomon, S., Qin, D., Manning, M., Chen, Z., Marquis, M., Averyt, K. B., Tignor, M., and Miller, H. L., 289-348, Cambridge Univ. Press, New York, 2007.

Fotheringham, A. S. and Wong, D. W.: The modifiable areal unit problem in multivariate statistical analysis, Environment and Planning A, 23, 1025-1044, 1991.

Garrett, T. J., Zhao, C., Dong, X., Mace, G. G., and Hobbs, P. V.: Effects of varying aerosol regimes on low-level Arctic stratus, Geophys. Res. Lett., 31, L17105, doi:10.1029/2004GL019928, 2004.

Gerber, H., Jensen, J. B., Davis, A. B., Marshak, A., and Wiscombe, W. J.: Spectral density of cloud liquid water content at high frequencies, J. Atmos. Sci., 58, 497-503, 2001.

Grandey, B. S. and Stier, P.: A critical look at spatial scale choices in satellite-based aerosol indirect effect studies, Atmos. Chem. Phys., 10, 11459-11470, doi:10.5194/acp-10-11459-2010, 2010.

Gultepe, I., Isaac, G. A., Leaitch, W. R., and Banic, C. M.: Parameterizations of marine stratus microphysics based on in-situ observations: Implications for GCMs, J. Clim., 9, 345-357, 1996.

Hubanks, P. A., King, M. D., Platnick, S., and Pincus, R.: MODIS Atmosphere L3 Gridded Product Algorithm Theoretical Basis Document, MODIS Algorithm Teoretical Basis Document No. ATBD-MOD-30, 2008.

Jelinski, D. E. and Wu, J.: The modifiable areal unit problem and implications for landscape ecology, Landscape Ecology, 11, 129-140, 1996.

Kaufman, Y. J., Koren, I., Remer, L. A., Rosenfeld, D., and Rudich, Y.: The effect of smoke, dust, and pollution aerosol on shallow cloud development over the Atlantic Ocean, P. Natl. Acad. Sci., 102, 11207-11212, doi:10.1073/pnas.0505191102, 2005.

Kim, B.-G., Schwartz, S. E., Miller, M. A., and Min, Q.: Effective radius of cloud droplets by ground-based remote sensing: Relationship to aerosol, J. Geophys. Res., 108, 4740, doi:10.1029/2003JD003721, 2003.

Kim, B.-G., Miller, M. A., Schwartz, S. E., Liu, Y., and Min, Q.: The role of adiabaticity in the aerosol first indirect effect, J. Geophys. Res., 113, D05210, doi:10.1029/2007JD008961, 2008.

Krueger, S. K., Su, C.-W., and McMurtry, P. A.: Modeling Entrainment and Finescale Mixing in Cumulus Clouds, J. Atmos. Sci., 54, 2697-2712, 1997.

Koren, I., Feingold, G., Jiang, H., and Altaratz, O.: Aerosol effects on the inter-cloud region of a small cumulus cloud field, Geophys. Res. Lett., 36, L14805, doi:10.1029/2009gl037424, 2009.

Lee, I.-Y. and Pruppacher, H. R.: A comparative study on the 
growth of cloud droplets by condensation using an air parcel morel with and without entrainment, Pure Appl. Geophys., 115, 523-545, 1977.

Lebsock M. D., Stephens, G. L., and Kummerow, C.: Multisensor satellite observations of aerosol effects on warm clouds, J. Geophys. Res., 113, D15205, doi:10.1029/2008JD009876, 2008.

Lee, I.-Y. and Pruppacher, H. R.: A comparative study on the growth of cloud drops by condensation using an air parcel model with and without entrainment, Pure Appl. Geophys., 115, 523545, doi:10.1007/BF00876119, 1977.

Levy, R. C., Leptoukh, G. G., Kahn, R., Zubko, V., Gopalan, A., and Remer, L. A.: A Critical Look at Deriving Monthly Aerosol Optical Depth From Satellite Data, IEEE T. Geosci. Remote Sens., 47, 2942-2956, doi:10.1109/TGRS.2009.2013842, 2009.

Lihavainen, H., Kerminen, V.-M., Komppula, M., Hyvärinen, A.-P., Laakia, J., Saarikoski, S., Makkonen, U., Kivekäs, N., Hillamo, R., Kulmala, M., and Viisanen, Y.: Measurements of the relation between aerosol properties and microphysics and chemistry of low level liquid water clouds in Northern Finland, Atmos. Chem. Phys., 8, 6925-6938, doi:10.5194/acp-8-6925-2008, 2008.

Lohmann, U., Rotstayn, L., Storelvmo, T., Jones, A., Menon, S., Quaas, J., Ekman, A. M. L., Koch, D., and Ruedy, R.: Total aerosol effect: radiative forcing or radiative flux perturbation?, Atmos. Chem. Phys., 10, 3235-3246, doi:10.5194/acp-10-32352010, 2010.

Lu, M.-L., Conant, W. C., Jonsson, H. H., Varutbangkul, V., Flagan, R. C., and Seinfeld, J. H.: The Marine Stratus/ Stratocumulus Experiment (MASE): Aerosol-cloud relationships in marine stratocumulus, J. Geophys. Res., 112, D10209, doi:10.1029/2006JD007985, 2007.

Lu, M.-L., Feingold, G., Jonsson, H. H., Chuang, P. Y., Gates, H., Flagan, R. C., and Seinfeld, J. H.: Aerosol-cloud relationships in continental shallow cumulus, J. Geophys. Res., 113, D15201, doi:10.1029/2007JD009354, 2008.

Martin, G. M., Johnson, D. W., and Spice, A.: The measurement and parameterization of effective radius of droplets in warm stratocumulus clouds, J. Atmos. Sci., 51, 1823-1842, 1994.

Matsui, T., Masunaga, H., Kreidenweis, S. M., Pielke, R. A., Tao, W.-K., Chin, M., and Kaufman, Y. J.: Satellite-based assessment of marine low cloud variability associated with aerosol, atmospheric stability, and the diurnal cycle, J. Geophys. Res., 111, D17204, doi:10.1029/2005JD006097, 2006.

McComiskey, A. and Feingold, G.: Quantifying error in the radiative forcing of the first aerosol indirect effect, Geophys. Res. Lett., 35, L02810, doi:10.1029/2007GL032667, 2008.

McComiskey, A., Feingold, G., Frisch, A. S., Turner, D. D., Miller, M. A., Chiu, J. C., Min, Q., and Ogren, J. A.: An assessment of aerosol-cloud interactions in marine stratus clouds based on surface remote sensing, J. Geophys. Res., 114, D09203, doi:10.1029/2008JD011006, 2009.

McFarquhar, G. M. and Heymsfield, A. J.: Parameterizations of INDOEX microphysical measurements and calculations of cloud susceptibility: Applications for climate studies, J. Geophys. Res., 106, 28675-28698, 2001.

Medeiros, B., Stevens, B., Held, I. M., Zhao, M., Williamson, D. L., Olson, J. G., and Bretherton, C. S.: Aquaplanets, Climate Sensitivity, and Low Clouds, J. Clim., 21, 4974-4991, 2008.

Murphy, D., Solomon, S., Portmann, R., Rosenlof, K., Forster, P., and Wong, T.: An observationally based energy balance for the Earth since 1950, J. Geophys. Res., 114, D17107, doi:10.1029/2009jd012105, 2009.

Nakajima, T., Higurashi, A., Kawamoto, K., and Penner, J. E.: A possible correlation between satellite-derived cloud and aerosol micro- physical parameters, Geophys. Res. Lett., 28, 1171-1174, 2001.

O’Dowd, C. D., Lowe, J. A., Smith, M. H., and Kaye, A. D.: The relative importance of sea-salt and nss- sulphate aerosol to the marine CCN population: An improved multi- component aerosol-droplet parameterization, Q. J. Roy. Meteorol. Soc., 125, 1295-1313, 1999.

Openshaw, S.: The Modifiable Areal Unit Problem, Concepts and Techniques in Modern Geography, No. 38, 1984.

Oreopolous, L., Marshak, A., Cahalan, R. F., and Wen, G.: Cloud three-dimensional effects evidenced in Landsat spatial power spectra and autocorrelation functions, J. Geophys. Res., 105, 14777-14788, 2000.

Platnick, S., King, M. D., Ackerman, S. A., Menzel, W. P., Baum, B. A., Riédi, J. C., and Frey, R. A.: The MODIS Cloud Products: Algorithms and Examples From Terra, IEEE T. Geosci. Remote, 41, 459-473, 2003.

Quaas, J., Boucher, O., and Breon, F.-M.: Aerosol indirect effects in POLDER satellite data and the Laboratoire de Meteorologie Dynamique-Zoom (LMDZ) general circulation model, J. Geophys. Res., 109, D08205, doi:10.1029/2003JD004317, 2004.

Quaas, J., Boucher, O., and Lohmann, U.: Constraining the total aerosol indirect effect in the LMDZ and ECHAM4 GCMs using MODIS satellite data, Atmos. Chem. Phys., 6, 947-955, doi:10.5194/acp-6-947-2006, 2006.

Quaas, J., Boucher, O., Bellouin, N., and Kinne, S.: Satellite-based estimate of the direct and indirect aerosol climate forcing, J. Geophys. Res., 113, D05204, doi:10.1029/2007JD008962, 2008.

Quaas, J., Ming, Y., Menon, S., Takemura, T., Wang, M., Penner, J. E., Gettelman, A., Lohmann, U., Bellouin, N., Boucher, O., Sayer, A. M., Thomas, G. E., McComiskey, A., Feingold, G., Hoose, C., Kristjánsson, J. E., Liu, X., Balkanski, Y., Donner, L. J., Ginoux, P. A., Stier, P., Grandey, B., Feichter, J., Sednev, I., Bauer, S. E., Koch, D., Grainger, R. G., Kirkevåg, A., Iversen, T., Seland, Ø., Easter, R., Ghan, S. J., Rasch, P. J., Morrison, H., Lamarque, J.-F., Iacono, M. J., Kinne, S., and Schulz, M.: Aerosol indirect effects general circulation model intercomparison and evaluation with satellite data, Atmos. Chem. Phys., 9, 8697-8717, doi:10.5194/acp-9-8697-2009, 2009.

Raga, G. B. and Jonas, P. R.: On the link between cloud-top radiative properties and sub-cloud aerosol concentrations, Q. J. Roy. Meteorol. Soc., 119, 1419-1425, 1993.

Ramanathan, V., Crutzen, J., Kiehl, J. T., and Rosenfeld, D.: Aerosols, climate, and the hydrological cycle, Science, 294, 2119-2124, 2001.

Remer, L. A., Kaufman, Y. J., Tanre, D., Matoo, S., Chu, D. A., Martins, J. V., Li, R.-R., Ichoku, C., Levy, R. C., Kleidman, R. G., Eck, T. F., Vermote, E., and Holben, B. N.: The MODIS Aerosol Algorithm, Products, and Validation, J. Atmos. Sci., 62, 947-973, 2005.

Roberts, G. C., Ramana, M. V., Corrigan, C., Kim, D., and Ramanathan, V.: Simultaneous observations of aerosolcloud-albedo interactions with three stacked unmanned aerial vehicles, P. Natl. Acad. Sci., 105, 7370-7375, doi:10.1073/pnas.0710308105, 2008. 
Robinson, W. S.: Ecological Correlations and the Behavior of Individuals, American Sociological Review, 15, 351-357, 1950.

Schwartz, S. E., Harshvardhan, and Benkovitz, C. M.: Influence of anthropogenic aerosol on cloud optical depth and albedo shown by satellite measurements and chemical transport modeling, $\mathrm{P}$. Natl. Acad. Sci., 99, 1784-1789, 2002.

Sekiguchi, M., Nakajima, T., Suzuki, K., Kawamoto, K., Higurashi, A., Rosenfeld, D., Sano, I., and Mukai, S.: A study of the direct and indirect effects of aerosols using global satellite data sets of aerosol and cloud parameters, J. Geophys. Res., 108, 4699, doi:10.1029/2002JD003359, 2003.

Shinozuka, Y. and Redemann, J.: Horizontal variability of aerosol optical depth observed during the ARCTAS airborne experiment, Atmos. Chem. Phys., 11, 8489-8495, doi:10.5194/acp-11-84892011, 2011.

Sorooshian, A., Feingold, G., Lebsock, M. D., Jiang, H. L., and Stephens, G. L.: On the precipitation susceptibility of clouds to aerosol perturbations. Geophys. Res. Lett., 36, L13803, doi:10.1029/2009GL038993, 2009.

Stevens, B., Lenschow, D. H., Vali, G., Gerber, H., Bandy, A., Blomquist, B., Brenguier, J.-L., Bretherton, C. S., Burnet, F., Campos, T., Chai, S., Faloona, I., Friesen, D., Haimov, S., Laursen, K., Lilly, D. K., Loehrer, S. M., Malinowski, S. P., Morley, B., Petters, M. D., Rogers, D. C., Russell, L., SavicJovcic, V., Snider, J. R., Straub, D., Szumowski, M. J., Takagi, H., Thornton, D. C., Tschudi, M., Twohy, C., Wetzel, M., and van Zanten, M. C.: Dynamics and Chemistry of Marine Stratocumulus - DYCOMS-II, B. Am. Meteorol. Soc., 84, 579-593, doi:10.1175/BAMS-84-5-579, 2003.
Twomey, S.: Pollution and the planetary albedo, Atmos. Environ., 8, 1251-1256, 1974.

Twohy, C. H., Petters, M. D., Snider, J. R., Stevens, B., Tahnk, W., Wetzel, M., Russell, L., and Burnet, F.: Evaluation of the aerosol indirect effect in marine stratocumulus clouds: Droplet number, size, liquid water path, and radiative impact, J. Geophys. Res., 110, D08203, doi:10.1029/2004JD005116, 2005.

Wang, H. and Feingold, G.: Modeling Mesoscale Cellular Structures and Drizzle in Marine Stratocumulus. Part I: Impact of Drizzle on the Formation and Evolution of Open Cells, J, Atmos. Sci., 66, 3237-3256, doi:10.1175/2009JAS3022.1, 2009.

Wood, R. and Hartmann, D. L.: Spatial Variability of Liquid Water Path in Marine Low Cloud: The Importance of Mesoscale Cellular Convection, J. Clim., 19, 1748-1764, 2006.

Xue, H., Feingold, G., and Stevens, B.: Aerosol effects on clouds, precipitation, and the organization of shallow cumulus convection, J. Atmos. Sci., 65, 392-406; doi:10.1175/2007JAS2428.1, 2008.

Zinner, T. and Mayer, B.: Remote sensing of stratocumulus clouds: Uncertainties and biases due to inhomogeneity, J. Geophys. Res., 111, D14209, doi:10.1029/2005JD006955, 2006. 